\title{
Identification of novel inner membrane complex and apical annuli proteins of the malaria parasite Plasmodium falciparum
}

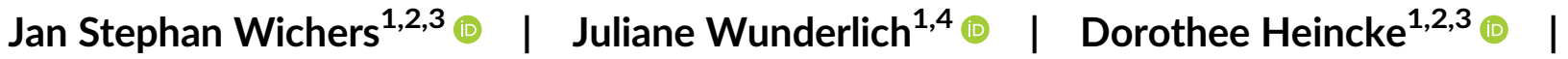

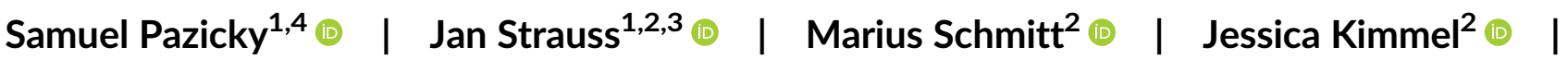 \\ Louisa Wilcke ${ }^{1,2,3}$ @ | Sarah Scharf ${ }^{2}$ (1) | Heidrun von Thien ${ }^{1,2,3}$ |

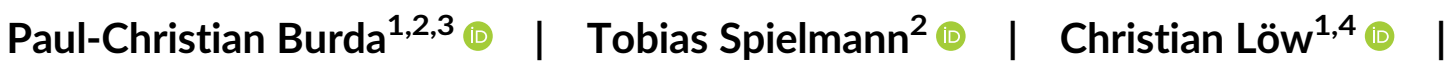 \\ Michael Filarsky ${ }^{1,3}$ ๑ | Anna Bachmann ${ }^{1,2,3,5}$ ๑ | Tim W. Gilberger, ${ }^{1,2,3} \odot$
}

${ }^{1}$ Centre for Structural Systems Biology, Hamburg, Germany

${ }^{2}$ Bernhard Nocht Institute for Tropical Medicine, Hamburg, Germany

${ }^{3}$ University of Hamburg, Hamburg, Germany

${ }^{4}$ European Molecular Biology Laboratory, Hamburg Unit, Hamburg, Germany

${ }^{5}$ German Centre for Infection Research (DZIF), partner site Hamburg-Borstel-Lübeck-Riems,

Braunschweig, Germany

Correspondence

Tim W. Gilberger, Centre for Structural Systems Biology, 22607 Hamburg, Germany. Email: gilberger@bnitm.de

Funding information

Boehringer Ingelheim Stiftung; CSSB Seed grant, Grant/Award Number: KIF 2019/002; Deutsche Forschungsgemeinschaft, Grant/ Award Number: BA 5213/3-1; Jürgen Manchot Stiftung; Landesforschungsförderung Hamburg, Grant/Award Number: LFF FV-69; Partnership of Universität Hamburg and DESY (PIER), Grant/Award Number: PIF-2018-87

\begin{abstract}
The inner membrane complex (IMC) is a defining feature of apicomplexan parasites, which confers stability and shape to the cell, functions as a scaffolding compartment during the formation of daughter cells and plays an important role in motility and invasion during different life cycle stages of these single-celled organisms. To explore the IMC proteome of the malaria parasite Plasmodium falciparum we applied a proximity-dependent biotin identification (BiolD)-based proteomics approach, using the established IMC marker protein Photosensitized INA-Labelled protein 1 (PhIL1) as bait in asexual blood-stage parasites. Subsequent mass spectrometry-based peptide identification revealed enrichment of 12 known IMC proteins and several uncharacterized candidate proteins. We validated nine of these previously uncharacterized proteins by endogenous GFP-tagging. Six of these represent new IMC proteins, while three proteins have a distinct apical localization that most likely represents structures described as apical annuli in Toxoplasma gondii. Additionally, various Kelch13 interacting candidates were identified, suggesting an association of the Kelch13 compartment and the IMC in schizont and merozoite stages. This work extends the number of validated IMC proteins in the malaria parasite and reveals for the first time the existence of apical annuli proteins in P. falciparum. Additionally, it provides evidence for a spatial association between the Kelch13 compartment and the IMC in late blood-stage parasites.
\end{abstract}

\section{1 | INTRODUCTION}

Plasmodium sp. are members of the phylogenetic clade Alveolata that comprises a diverse group of unicellular eukaryotes including wellestablished phylogenetic groups such as Ciliates, Dinoflagellates and
Apicomplexa (Cavalier-Smith, 1993). A defining feature of the Alveolata is a double-membrane system underlying the plasma membrane that is termed "alveoli" in ciliates and dinoflagellates (Allen, 1971; Lee \& Kugrens, 1992) or collectively "inner membrane complex" (IMC) in apicomplexan parasites (Morrissette \& 
Sibley, 2002). The IMC underlies the plasma membrane of the cell and consists of flattened double-membrane vesicles (Morrissette \& Sibley, 2002) that are integrated into cytoskeletal components (Fowler, Fookes, Lavin, Bannister, \& Mitchell, 1998; Russell \& Burns, 1984; Tran et al., 2010). During evolution, this unique compartment was adapted to the individual ecological niches of the different clades (Kono, Prusty, Parkinson, \& Gilberger, 2013). This is reflected in the architecture and proteome of the IMC. For apicomplexans, the IMC has three main functions: (a) it plays a major role in motility and invasion, (b) it confers stability and shape to the cell and (c) it provides a scaffolding framework during cytokinesis (Ferreira et al., 2021; Harding \& Frischknecht, 2020). While the IMC of the motile stages serves as the anchor for proteins involved in gliding motility and host cell invasion (Baum, Gilberger, Frischknecht, \& Meissner, 2008; Perrin et al., 2018; Soldati, Foth, \& Cowman, 2004), the gametocyte IMC appears to serve a structural role (Dearnley et al., 2012; Parkyn Schneider et al., 2017; Sinden, 1982). The IMC is generated de novo from Golgi-derived material in each replication cycle of the parasite during cytokinesis (Bannister, Hopkins, Fowler, Krishna, \& Mitchell, 2000). This is similar to other compartments such as the secretory organelles that assemble a subset of parasite proteins crucial for invasion, egress and host cell modification (Blackman \& Bannister, 2001).

To date about 45 IMC proteins have been identified in Plasmodium (Ferreira et al., 2021), however, there is no comprehensive proteomic analysis of this structure available. From the confirmed IMC proteins it is evident that in addition to a common core set of conserved proteins found in all Alveolata, such as the Alveolins (Gould et al., 2011; Gould, Tham, Cowman, McFadden, \& Waller, 2008), the IMC includes many lineage-specific proteins, reflecting additional specialized roles (Kono et al., 2012). A functional specialization is exemplified by a group of well-characterized proteins that form the so-called glideosome-the motor complex that drives the locomotion of all motile apicomplexan parasite stages (Gaskins et al., 2004; Jones, Kitson, \& Rayner, 2006; Keeley \& Soldati, 2004)-anchored into the IMC. Another example of an apicomplexan-specific IMC protein is Photosensitized INA-Labelled protein 1 (PhIL1), which was first identified as an IMC protein in Toxoplasma (Gilk et al., 2006) and is well characterized in both Plasmodium (Campelo Morillo et al., 2020; Parkyn Schneider et al., 2017; Saini et al., 2017) and Toxoplasma (Barkhuff et al., 2011; Gilk et al., 2006). The Plasmodium falciparum PhIL1 (PF3D7_0109000) consists of 224 amino acids, was shown to be essential for mature gametocyte formation (Parkyn Schneider et al., 2017) and was characterized as likely essential in blood-stage parasites (Zhang et al., 2018). This is supported by the reported failed attempts in generating knockout parasites inPlasmodium berghei asexual blood stage (Saini et al., 2017) and by PlasmoGEM data (Bushell et al., 2017), even though no growth defect was observed upon gImSbased conditional knockdown in P. falciparum (Parkyn Schneider et al., 2017). Proteins such as MORN1 (Ferguson et al., 2008; Gubbels, Vaishnava, Boot, Dubremetz, \& Striepen, 2006), CINCH (Rudlaff, Kraemer, Streva, \& Dvorin, 2019) or BTP1 (Kono et al., 2016) define a sub-compartment of the IMC termed the basal complex. The

\section{Take Away}

- Six novel IMC proteins are identified using PhIL1 based BiolD and and their redundancy probed by conditional knockdown and reverse genetics.

- "Apical Annuli Proteins" are localized in P. falciparum.

- A spatial association between the PfKelch13 compartment and the IMC is shown.

basal complex represents a dynamic ring structure and is implicated in organelle division of maturing daughter cells (Rudlaff et al., 2019). The basal complex migrates distally away from the apical end of the daughter cells, marking the basal end of the newly formed parasite (Ferguson et al., 2008; Gubbels et al., 2006; Hu, 2008; Hu et al., 2006; Kono et al., 2016).

Additionally, another intriguing substructure is embedded in the apical area of the IMC-the apical annuli. These structures were first discovered in Toxoplasma gondii (Hu et al., 2006) and defined by cluster of rings with diameters ranging from 200 to $400 \mathrm{~nm}$ (Engelberg et al., 2019; Hu et al., 2006) containing TgCentrin2 (Lentini, Dubois, Maco, SoldatiFavre, \& Frénal, 2019; Leung, Liu, Wetzel, \& Hu, 2019) and at least six other apical annuli proteins (TgAAP1-5, TgAAMT) (Engelberg et al., 2019; Suvorova, Francia, Striepen, \& White, 2015). AAPs, like many other IMC proteins, are specific for apicomplexan parasites and show similarity to centrosomal proteins (Engelberg et al., 2019). Two AAP homologues were identified in the genome of $P$. falciparum but have not been further characterized yet (Engelberg et al., 2019).

Here we used proximity-dependent biotinylation (BiolD) with PfPhIL1 to better characterize the IMC proteome and determine the interactome of this protein. BiolD approaches have been previously successfully applied to identify IMC proteins of $T$. gondii (Chen et al., 2015; Chen et al., 2017) as well as novel components of several Plasmodium organelles (Birnbaum et al., 2020; Boucher et al., 2018; Geiger et al., 2020; Kehrer et al., 2020; Kehrer, Frischknecht, \& Mair, 2016; Khosh-Naucke et al., 2018; Schnider, Bausch-Fluck, Brühlmann, Heussler, \& Burda, 2018).

This work identifies six novel IMC proteins, termed PhIL1 interacting candidates (PIC) as well as three putative apical annuli proteins, providing evidence for this structure in malaria parasites.

\section{2 | RESULTS}

\section{1 | Identification of PhIL1-interacting proteins by BiolD}

The well-established, abundantly expressed PfPhIL1 protein was used to identify putative PhIL1 interaction candidates and novel IMC proteins. For this, we employed BiolD (Roux, Kim, Raida, \& Burke, 2012) that exploits the activity of the biotin ligase BirA* for protein 
(a)

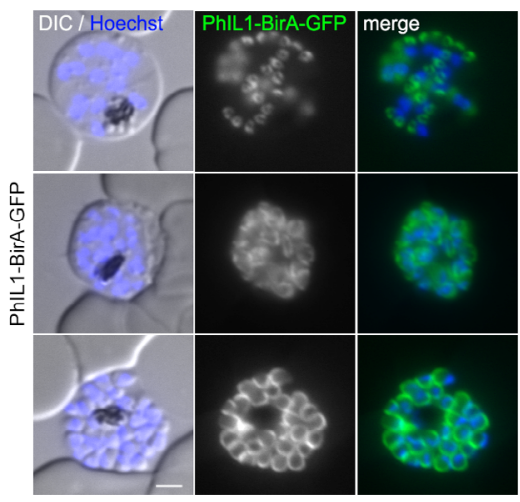

(d)

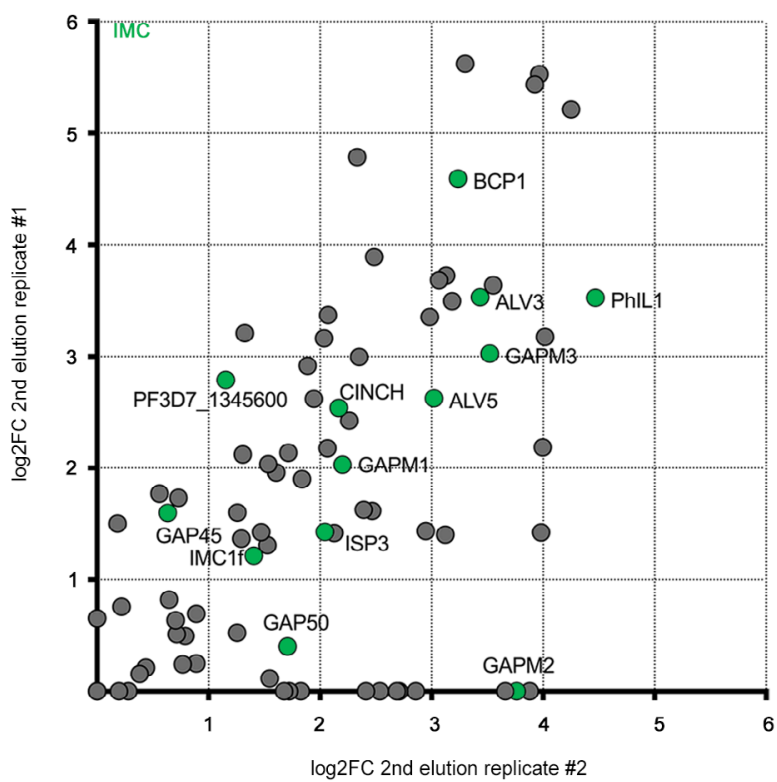

(f)

\begin{tabular}{ccc}
\hline accession PlasmoDB & annotation & $\begin{array}{c}\text { mean log2 FC } \\
\text { 2nd elution }\end{array}$ \\
\hline PF3D7_1229300 & conserved Plasmodium protein, unknown function (PIC1) & 4.75 \\
PF3D7_0822900 & conserved Plasmodium protein, unknown function (PIC2) & 4.73 \\
PF3D7_0415800 & RING zinc finger protein, putative (PIC3) & 4.68 \\
PF3D7_0623800 & TKL4, putative & 4.46 \\
PF3D7_0109000 & PhIL1 & 4.00 \\
PF3D7_1436200 & BCP1 & 3.92 \\
PF3D7_0308300 & conserved Plasmodium protein, unknown function (PIC4) & 3.60 \\
PF3D7 0203000 & ROPE, putative & 3.60 \\
PF3D7_1019000 & eukaryotic translation initiation factor subunit elF2A, putative & 3.56 \\
PF3D7 0525800 & IMC1g & 3.48 \\
PF3D7_0613900 & myosin E, putative & 3.43 \\
PF3D770508900 & conserved Plasmodium protein, unknown function (AAP6) & 3.38 \\
PF3D7_1014900 & KIC8 & 3.34 \\
PF3D7_1406800 & GAPM3 & 3.27 \\
PF3D71318700 & AAP4, putative & 3.24 \\
PF3D7_1438400 & MCA2, putative & 3.19 \\
PF3D7_1235200 & VP2 & 3.09 \\
\hline
\end{tabular}

(c)

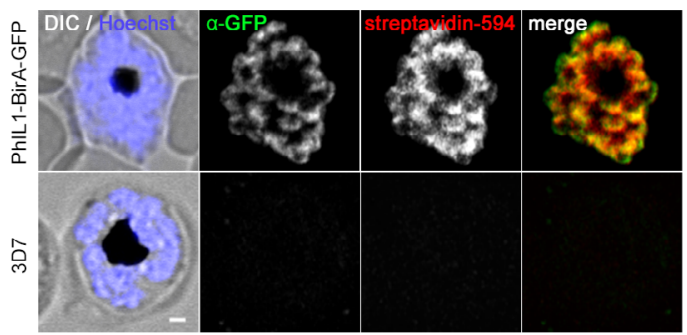

(e)

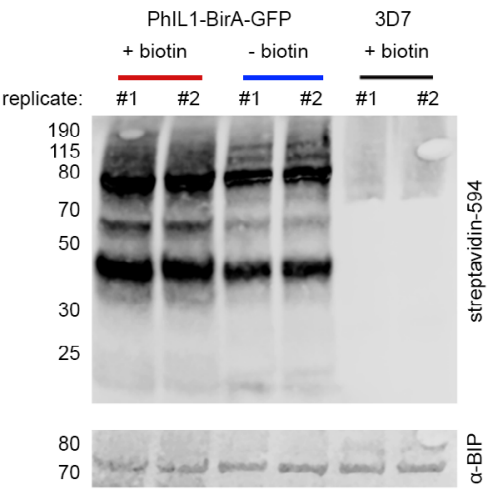

PF3D7_0109000 PF3D7_1436200 PF3D7_0525800 PF3D7_1406800

PF3D7_1229300 PF3D7_0822900 PF3D7_0415800 PF3D7_0623800 PF3D7 0308300 PF3D7_0203000 PF3D7 1019000 PF3D7_0613900 PF3D7 0508900 PF3D7_1014900 PF3D7_1318700 PF3D7 1438400 PF3D7 1235200

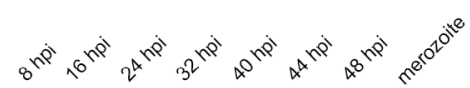

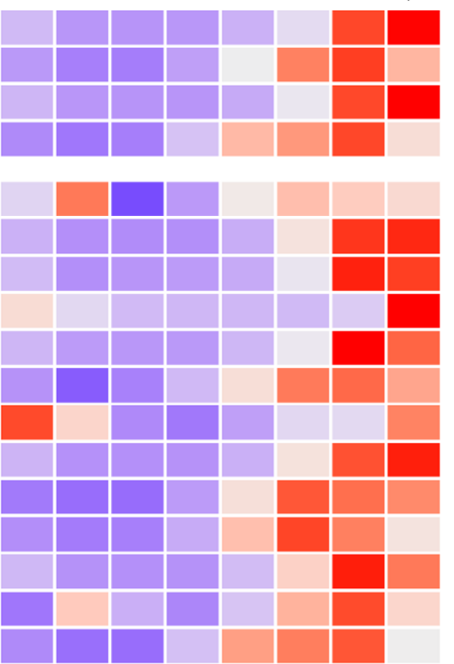

RNAseq gene expression ( $\log 2 \mathrm{FPKM})$

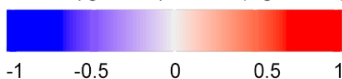

FIGURE 1 Identification of PhIL1-interacting candidates using BioID. (a) IMC localisation of PfPhIL1-BirA-GFP in schizonts and merozoites. Nuclei were stained with Hoechst-33,342. Scale bar, $2 \mu \mathrm{m}$. (b) PfPhIL1-based biotinylation at the IMC. PfPhIL1-BirA-GFP (mouse anti-GFP, green) or 3D7 control parasites were fixed with $\mathrm{MeOH}$ at the schizont stage and biotinylated proteins were visualized by streptavidin-594 (red). Hoechst was used for DNA staining (blue). Scale bar, $1 \mu \mathrm{m}$. (c) Biotinylation in PhIL1-BirA-GFP and 3D7 parasites cultured in the presence of $150 \mu \mathrm{M}$ biotin (+ biotin) or PhIL1-BirA-GFP parasites cultured without biotin (-biotin) supplementation was visualized by streptavidin-594. AntiBIP was used as loading control. (d) Scatterplot showing proteins with a log2FC $\geq 0$ in both BiolD replicates. Green dots are indicating known IMC proteins. (e) Expression profiles (Wichers et al., 2019) of the 17 most enriched proteins from (d) represented as a heat map (established IMC proteins (green), candidates selected for further validation (blue)). (f) Proteins with a mean log2FC > 3 in the PfPhIL1-BirA-GFP compared to the 3D7 control sample are listed. For a complete list see Table S1. Known IMC proteins are highlighted in green, proteins marked in blue were selected for further validation 
biotinylation and allows determination of putative protein-protein interaction by subsequent mass spectrometry.

First, we generated the transgenic parasite line PfPhIL1-BirA-GFP by tagging the endogenous protein with Bir ${ }^{*}$ and green fluorescent protein (GFP) using the selection-linked integration (SLI) system (Birnbaum et al., 2017) (Figure S1a). Correct integration of the plasmid into the PfPhIL1 gene locus was verified by PCR (Figure S1b). Expression of the fusion protein in schizont-stage parasites was confirmed by Western blot using anti-GFP antibodies (Figure S1c). Widefield fluorescence microscopy confirmed the expected IMC localization pattern (Campelo Morillo et al., 2020; Parkyn Schneider et al., 2017; Saini et al., 2017) of PfPhIL1-BirA-GFP with an additional weak expression in ring stages (Figures 1a and S1d). Coexpression of the alveolin IMC protein ALV5 (Anderson-White et al., 2011; Gould et al., 2008; Hu et al., 2010) in the PhIL1-BirA-GFP parasites revealed an IMC-typical localization of both tagged proteins with different fluorescence intensities at the parasite periphery of the developing merozoites (Figure S1e).

Next, we investigated PfPhiL1-BirA-GFP dependent protein biotinylation in the presence and absence of $150 \mu \mathrm{M}$ biotin in tightly synchronized parasite cultures. A schematic of the experimental strategy is shown in Figure S1f. We visualized biotinylated proteins with fluorescent-labelled streptavidin by fluorescent microscopy revealing colocalization with our IMC marker PfPhiL1-BirA-GFP with no background staining in 3D7 control parasites (Figure 1b). The IMC specific biotinylation signal in PfPhIL-BirA-GFP parasites is also detectable without additional biotin (Figure S1g). These results are mirrored by Western blot analysis although biotinylation is more pronounced in parasite material cultivated with excess biotin (Figure 1c). This BirAdependent biotinylation in the absence of additional biotin was previously reported for Plasmodium infected cells (Khosh-Naucke et al., 2018; Schnider et al., 2018).

To account for this PfPhiL1-BirA-GFP-based biotinylation in the absence of additional biotin, the parental 3D7 parasites were used as a negative control in the subsequent mass spectrometry protein identification. Biotinylated proteins from two independent biological replicates were affinity-purified from schizont-stage parasite lysate using streptavidin sepharose. Affinity purified proteins were eluted first with ammonium bicarobonate ("first elution") and second with $80 \%$ acetonitrile/20\% trifluoroacetic acid ("second elution") to account for different protein affinity profiles. 219 proteins with a mean $\log _{2}$ fold change $>1$ in the first elutions and 58 proteins in the second elutions were identified. Proteins found to be enriched compared to the 3D7 control are shown in Figures $1 \mathrm{~d}, \mathrm{e}, \mathrm{S} 1 \mathrm{~h}$, and Table S1. The top 17 enriched proteins show a mean $\log _{2}$ fold change $>3$ and include four proteins that have been previously localized to the IMC or the basal complex: BCP1 (Rudlaff et al., 2019), ALV3 (Anderson-White et al., 2011; Gould et al., 2008; Hu et al., 2010), GAPM3 (Bullen et al., 2009) and the bait protein PhIL1 (Parkyn Schneider et al., 2017; Saini et al., 2017) (Figure 1d).

Genes coding for IMC proteins are typically characterized by a uniform transcriptional profile during asexual replication cycle with a maximum expression in the late schizont/merozoite stage (Hu et al., 2010). To filter out potential IMC proteins we thus discriminated enriched proteins by comparative analysis of the expression pattern of all candidates (Figure 1f). All genes except PF3D7_1019000 (putative eukaryotic translation initiation factor subunit eIF2A) exhibit the expected profile, therefore PF3D7_1019000 was excluded from further analysis.

Additionally, the following proteins were excluded based on published literature: PF3D7_1235200 (VP2) was previously localized to the parasite plasma membrane or punctate intracellular inclusions (Mclntosh, Drozdowicz, Laroiya, Rea, \& Vaidya, 2001), PF3D7_1014900 (KIC8) and PF3D7_1438400 (MCA2) are linked with the Kelch13 compartment (Birnbaum et al., 2020) and PF3D7_0613900 (MyoE) was shown to have a non-IMC like localization in P. berghei schizonts (Wall et al., 2019), resulting in a list of eight putative novel IMC proteins (PF3D7_1229300, PF3D7_0822900, PF3D7_0415800, PF3D7_0623800, PF3D7_0308300, PF3D7_0203000, PF3D7_0508900 and PF3D7_1318700). Additionally, we included PF3D7_1310700 and PF3D7_0530300, which weretogether with the known IMC protein GAPM2 (Bullen et al., 2009)-highly enriched in replicate \#2 ( $\log _{2}$ fold change of 2.86 and 2.69), but absent in the elutions of replicate \#1 (Table S1). This resulted in a final selection of 10 candidates for further analysis.

\subsection{Localization of PIC reveals six novel IMC proteins}

Based on their potential interaction with PhIL1, we named the previously non-annotated proteins PIC. The 10 selected candidate proteins were further validated. We first aimed to localize them by endogenous C-terminal GFP tagging using the SLI system. We achieved successful modification of the respective gene loci for eight candidate proteins (Figures 2, 3, and 4), while two genes, Pfrope (Werner, Taylor, \& Holder, 1998) (PF3D7_0203000) and pic5 (PF1310700), were refractory to $3^{\prime}$ modifications using the SLI system. From the resulting eight endogenously tagged cell lines, seven expressed the fusion protein to a sufficient level that allowed its subcellular localization, even though PIC3-GFP and PIC6-GFP expression levels were very weak (Figure 2a-e and S2). The TKL4 (Abdi, Eschenlauer, Reininger, \& Doerig, 2010)-GFP (PF3D7_0623800) expression level was too low for conclusive localization (Figure S2d). Fluorescence microscopy of PIC1-4 and 6 showed an IMC-typical localization pattern (Figures 2ae and S2). We verified the IMC localization by coexpression of the IMC marker protein ALV5 in the GFP-tagging cell lines (Figure 3).

Additionally, due to the lack of SLI-based integration into the PIC5 (PF3D7_1310700) locus, this protein was episomally expressed as a mCherry fusion in the PfPhIL1-BirA-GFP cell line. Again, an IMCtypical localization pattern was observed (Figures $2 f$ and 3 ) resulting in a total of six PIC proteins with IMC localization (PIC1-6).

\section{3 | Distinct localization of apical annuli protein homologues in $P$. falciparum}

Two other PICs identified by PhIL1-based BiolD, PF3D7_0508900-GFP and PF3D7_1318700-GFP (annotated in 
(a)

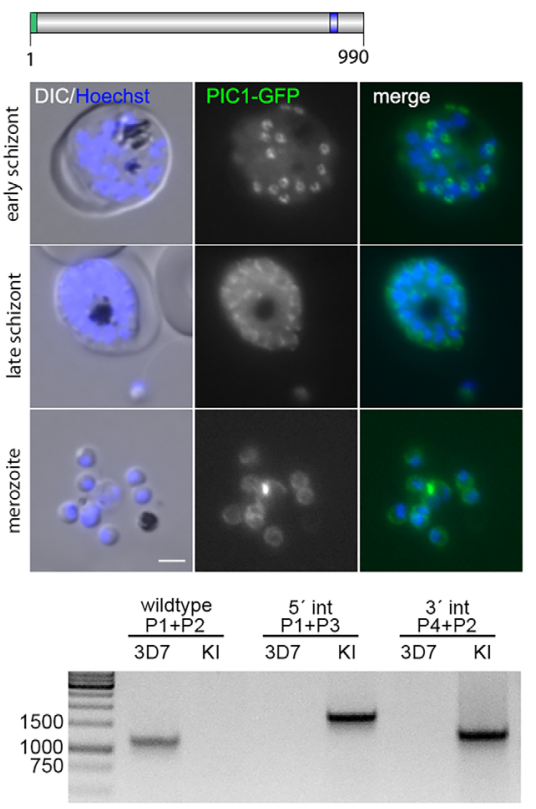

(d)

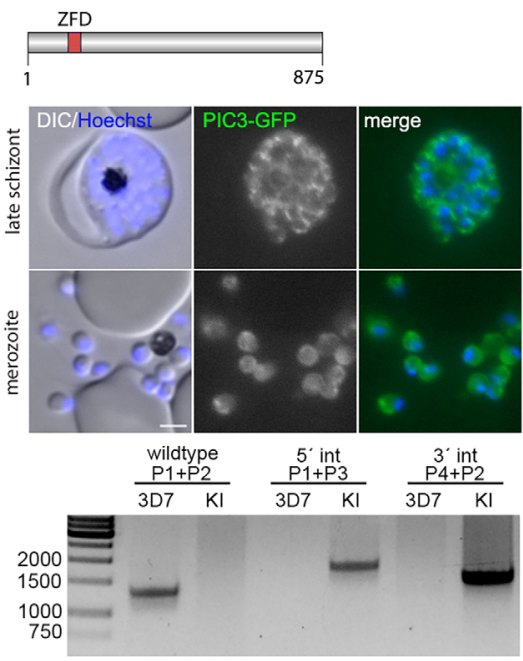

(b)

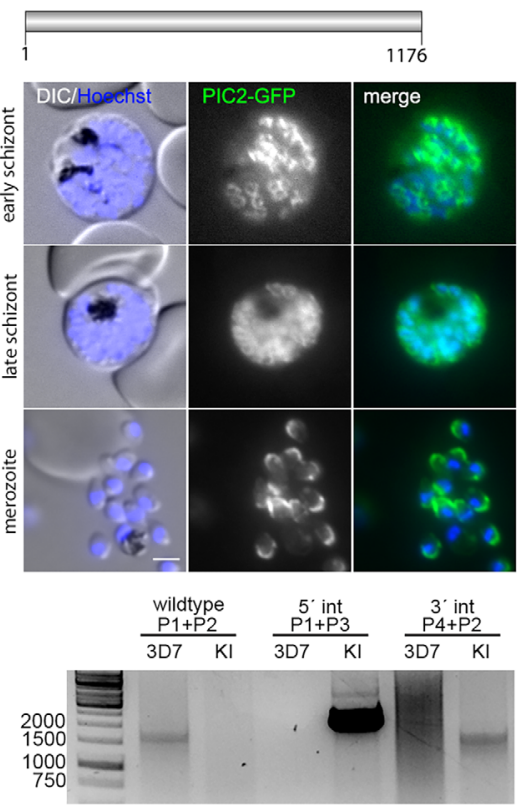

(e)

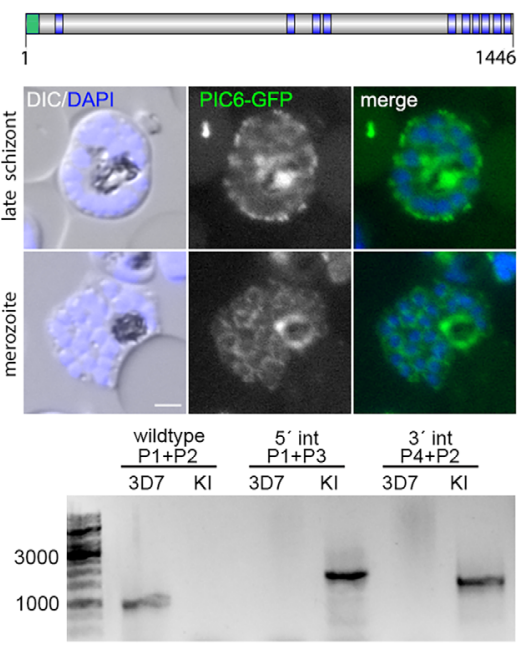

(c)

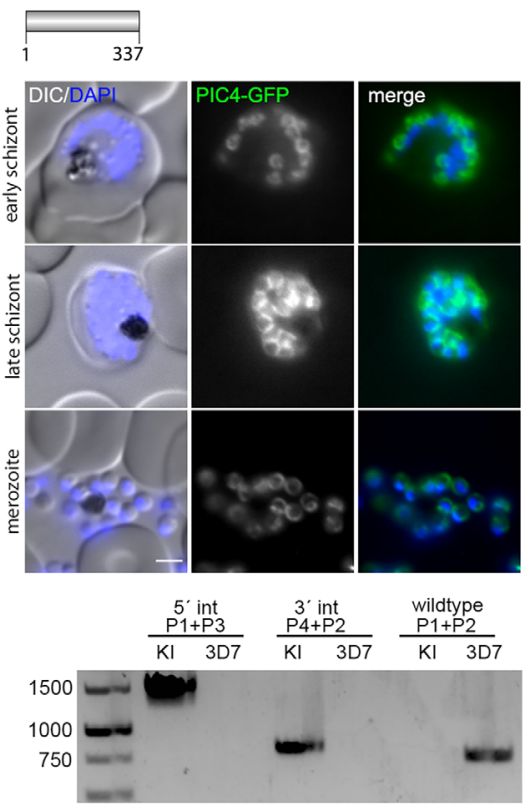

(f)

$$
\begin{array}{|c|c|}
\multicolumn{2}{c}{\text { RBD }} \\
\hline 1 & \text { | } \\
\hline 1 & 143
\end{array}
$$

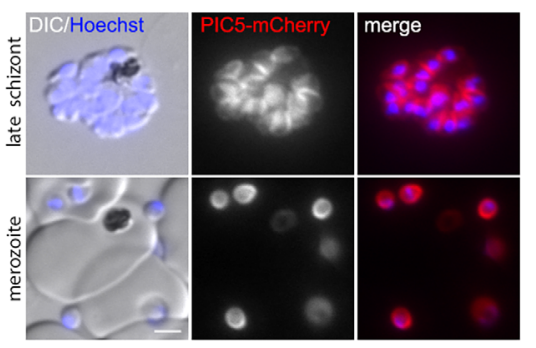

FIG URE 2 Localization of PhIL1 interacting candidates (PIC) using endogenous GFP tagging. (a) PIC1 (PF3D7_1229300), (b) PIC2 (PF3D7_0822900), (c) PIC4 (PF3D7_0308300), (d) PIC3 (PF3D7_0415800), (e): PIC6 (PF3D7_0530300): On top a schematic representation of the protein (protein length indicated as number of amino acids) with putative protein domains (blue, transmembrane domain; green, signal peptide; red, Zinc Finger domain (ZFD) or RBD (RNA binding domain). Localization of PIC-GFP fusion proteins in schizonts and free merozoites are shown in the middle panel, the PCR-based confirmations of the correct insertion of GFP-encoding integration plasmid into the targeted loci on the bottom. Ladder size indicated in base pairs (bp). gDNA from parental 3D7 was used as control. (f) Localization of PIC5-mCherry (PF3D7_1310700) fusion proteins episomally expressed under the control of the late-stage promoter ama1 in schizonts and free merozoites. Nuclei stained with Hoechst-33,342 or DAPI. Zoom factor: 400\%. Scale bar $2 \mu \mathrm{m}$. KI, knock-in

PlasmoDB as PfAAP4) showed a unique localization pattern clearly distinct from their IMC-localized counterparts (Figures 4a,b and S3).

PfAAP4 is the homologue of the apical annuli protein TgAAP4 (TGGT1_230340) that was recently described in T. gondii (Barylyuk et al., 2020; Engelberg et al., 2019). Homology searches of the list of enriched proteins from the BiolD experiment for further homologues of T. gondii apical annuli proteins retrieved PF3D7_1312800 (TgAAP2, TGGT1_295850) and PF3D7_1455200 (TgAAMT,
TGGT1_310070) (Figure S4). Accordingly, we named these two proteins PfAAP2 and PfAAMT. PF3D7_0508900 was annotated as PfAAP6, due to its localization similar to PfAAP2 and PfAAP4. Next, we generated an endogenously tagged PfAAP2-GFP cell line (Figure 4C), which revealed a similar localization to PfAAP6-GFP and PfAAP4-GFP. These three GFP fusion proteins localize at the apical pole in nascent daughter cells (Figure $4 a-c$ and S3). While PfAAP4-GFP could not be visualized in free merozoites (Figure 4b), 
(a)

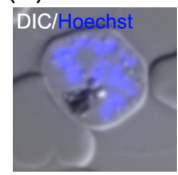

(b)

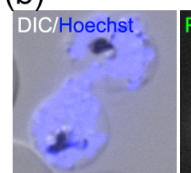

(c)

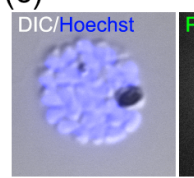

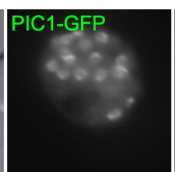

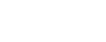

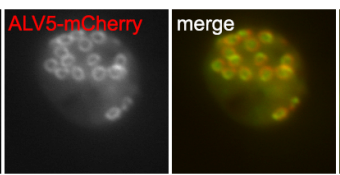
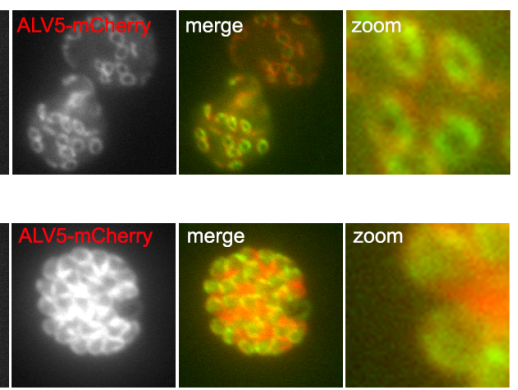

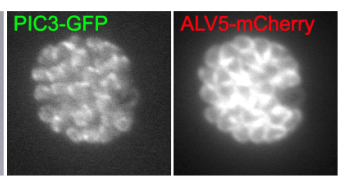

(d)
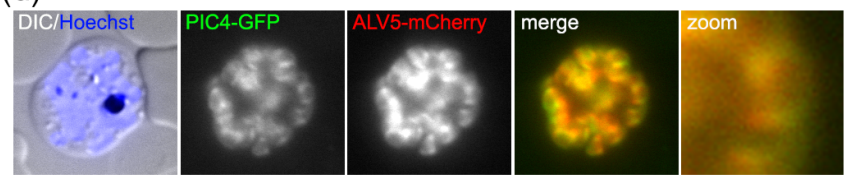

(e)
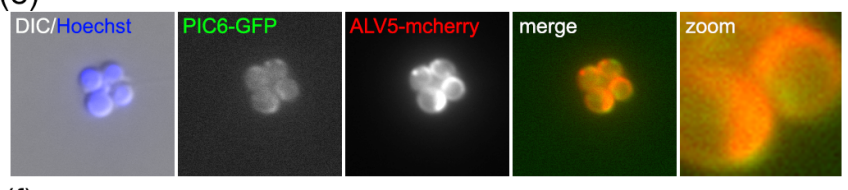

(f)
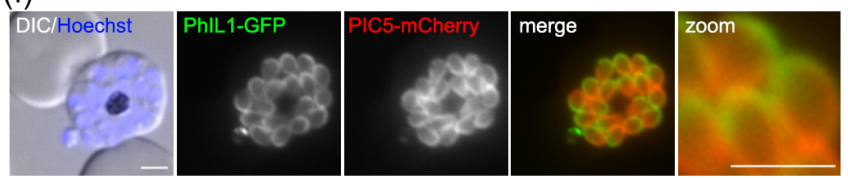

FIGURE 3 Coexpression of PICs with the IMC marker ALV5-mCherry. Coexpression of the candidate proteins PIC1 (a), PIC2 (b), PIC3 (c), PIC4 (d) and PIC6 (e) with the IMC marker protein ALV5 episomally expressed as mCherry fusion protein under the control of the late-stage promoter ama1. (f) PIC5 episomally expressed as mCherry fusion protein under the control of the late-stage promoter ama1 in PhIL1-BirA-GFP parasites. Nuclei stained with Hoechst-33,342. Zoom factor: $400 \%$. Scale bars $2 \mu \mathrm{m}$

PfAAP6-GFP and PfAAP2-GFP showed a weak signal (Figures 4a,c and S3).

To exclude a localization to the apical organelles, we colocalized PfAAP6-GFP and PfAAP4-GFP with appropriate marker proteins: PfARO (Cabrera et al., 2012; Geiger et al., 2020) (rhoptry bulb marker), PfRON12 (Ito et al., 2019; Knuepfer et al., 2014) or PfAIP (Geiger et al., 2020) (rhoptry neck marker) and PfAMA1 (Healer, Crawford, Ralph, McFadden, \& Cowman, 2002; Peterson et al., 1989) (micronemes marker) and additionally PfAAP4-GFP with PfEXP2 (Bullen et al., 2012; Mesén-Ramírez et al., 2019) (dense granules marker). To achieve this, we transfected the endogenously tagged PfAAP6-GFP and PfAAP4-GFP expressing cell lines with an expression plasmid for the respective mCherry fusion proteins (Figure $4 d, e$ ). This revealed that localization of both PfAAP6-GFP and PfAAP4-GFP is clearly distinct from-but spatially associated with-the apical organelles.

Super-resolution microscopy indicated that the apical annuli structures are embedded in the IMC in T. gondii (Engelberg et al., 2019). To probe into the spatial relation of the PfAAP4 defined apical annuli structure and the IMC in $P$. falciparum, we coexpressed it with the IMC marker protein ALV5 using fluorescence (Figure 4e) and structured illumination microscopy (SIM). IMC and apical annuli develop at the same time during early schizont development at the apical pole of nascent daughter cells. While the punctuated PfAAP4-GFP signal remains restricted to the apical area, the ALV5-mCherry signal expands with the IMC from the apical to the basal pole during the maturation of the daughter cells during late schizogony. While the PfAAP4-GFP signal is not in all instances clearly assigned to the ALV5-mCherry defined IMC structure, the putative annuli are clearly in the vicinity of the IMC and part of the expanding circular structure of the IMC (see T3 and T4 in Figure 4f). This suggests an embedment or the association of the PfAAP4 structure with the IMC. In late-stage schizonts and free merozoites the PfAAP4 signal is lost (Figure 4f).

\section{4 | Functional assessment of PIC1, PIC2, PIC3, PIC4, PfAAP4, PfAAP6 and PhIL1}

The introduction of a glmS ribozyme (Prommana et al., 2013) sequence upstream of the $3^{\prime}$ untranslated region in the pSLI plasmid allowed the conditional degradation of mRNA of PIC1, PIC2, PIC3, PfAAP4 and PfAAP6 upon glucosamine addition. First, we quantified the reduction of the GFP signal in the presence of $2.5 \mathrm{mM}$ glucosamine which showed that this leads to an $85.33 \%$ ( $S D \pm 1.97$ ) reduction of GFP fluorescence intensity in PIC1-GFP and to $46.39 \%$ (SD \pm 0.57 ) reduction in PIC3-GFP (Figures $5 \mathrm{a}, \mathrm{b}$ and $\mathrm{S} 5 \mathrm{~d}, \mathrm{e})$, but no reduction in PIC2-GFP and PfAAP4-GFP. The expression of PfAAP6-GFP in the absence of glucosamine was already too low to be reliably quantified (Figure S5f-h). Subsequently, for those cell lines that showed a significant reduction in the expression of endogenously tagged protein, PIC1-GFP and PIC3-GFP, parasite proliferation was analysed in the absence and presence of glucosamine. No significant growth defect could be observed (Figure 5a,b,d).

Due to the candidate-dependent knock-down efficacy with the gImS-based knock-down approach we also applied a conditional inactivation via the knock-sideways (Birnbaum et al., 2017) approach for one IMC protein (PIC4). In contrast to the RNA-based gImS method, this system allows the mislocalization of a protein from its site of action into the nucleus upon addition of rapalog and was shown highly effective for membrane-associated proteins such as PfRab5a (Birnbaum et al., 2017), PfKELCH13 (Birnbaum et al., 2020) and PfAIP (Geiger et al., 2020). To achieve mislocalization, we used our PIC4-2xFKBP-GFP-2xFKBP parasites line and transfected it with the 1xNLS-FRB-mCherry plasmid (Birnbaum et al., 2017) encoding the nuclear mislocalizer coupled to FRB-mCherry. Efficient mislocalization of PIC4-2xFKBP-GFP-2xFKBP into the nucleus upon addition of rapalog was shown by live-cell epifluorescence 
(a)

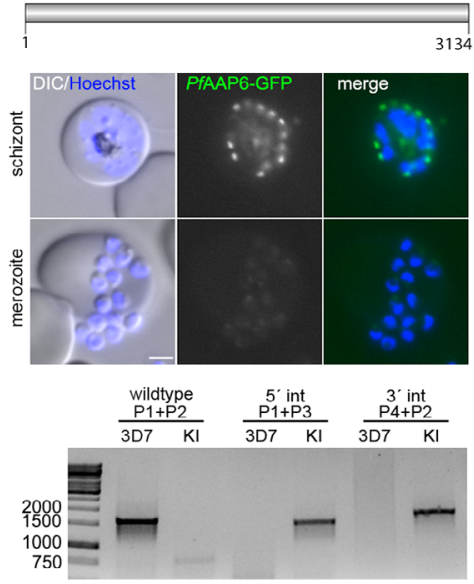

(d)

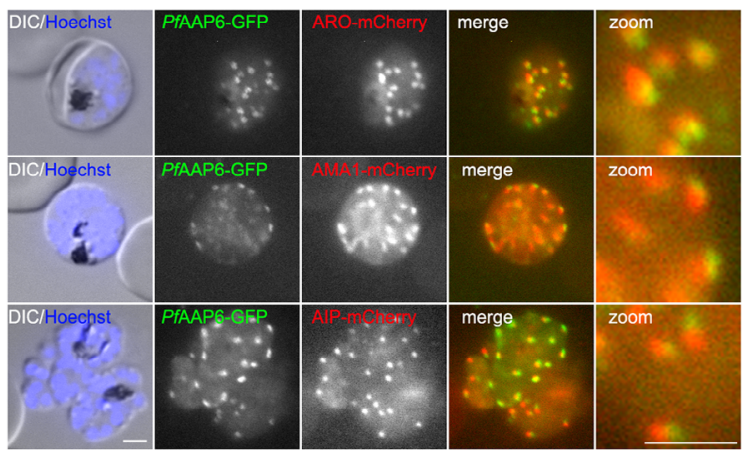

(e)

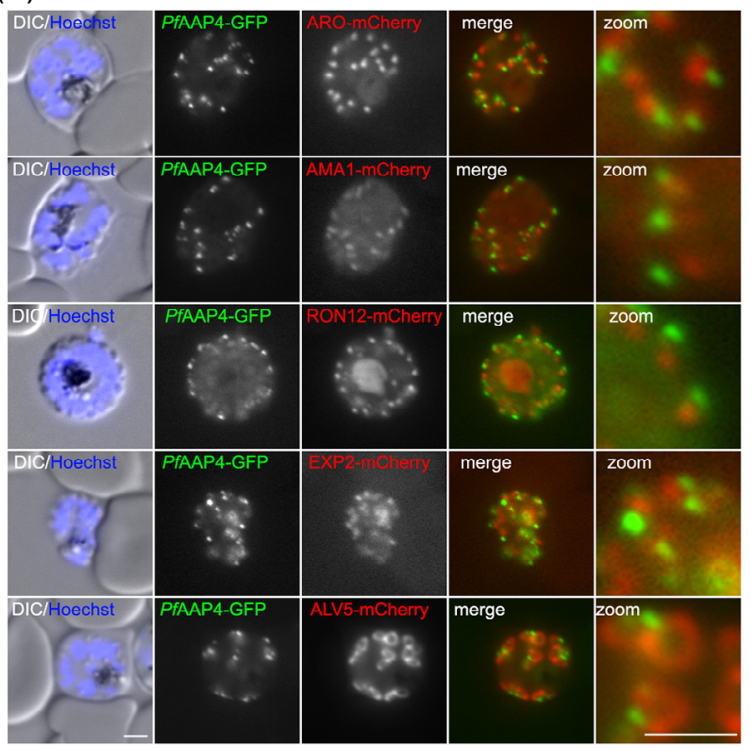

(b)

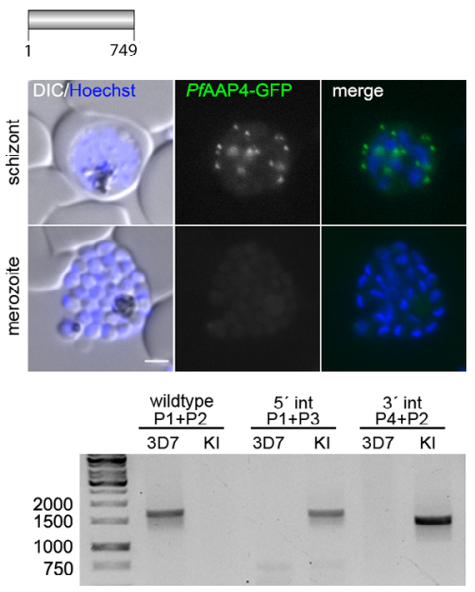

(c)

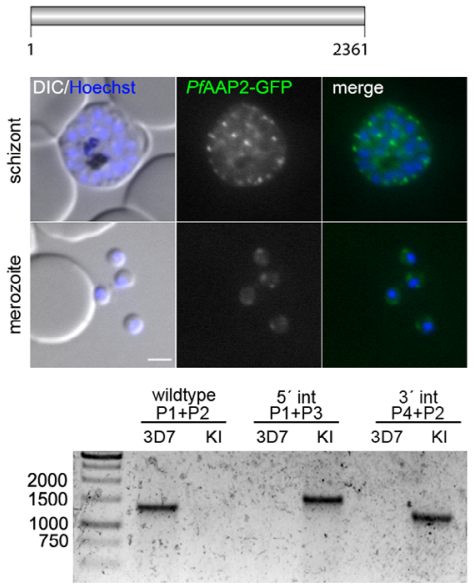

(f)

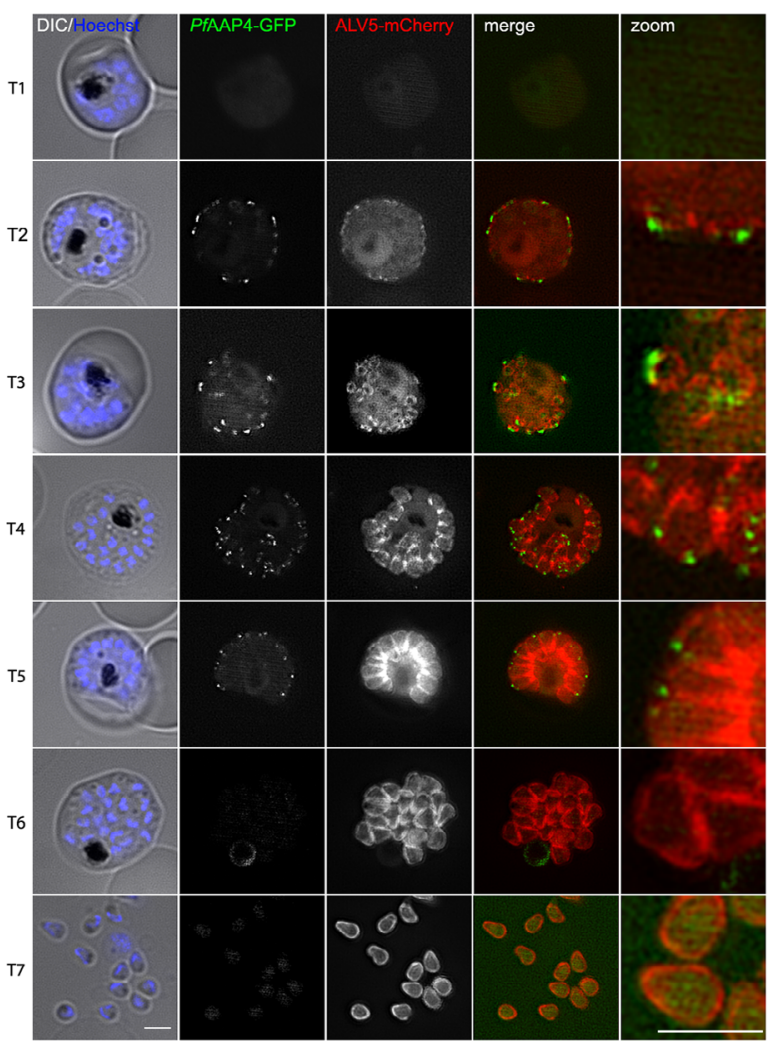

FIG URE 4 PfAAP6, PfAAP4 and PfAAP2 define a novel, apical structure in P. falciparum. (a) PfAAP6 (PF3D7_0508900), (b) PfAAP4 (PF3D7_1318700) and (c) PfAAP2 (PF3D7_1312800): Schematic representation of each protein (protein length indicated as number of amino acids) on top. Localization of AAP-GFP fusion proteins in schizonts and free merozoites and PCR-based confirmation of the correct insertion of GFP-encoding integration plasmid into the targeted loci shown underneath. Ladder size indicated in base pairs (bp). gDNA from parental 3D7 was used as control. Nuclei stained with Hoechst-33,342. Scale bars $2 \mu \mathrm{m}$. (d) Colocalization of PfAAP6-GFP with the rhoptry bulb marker protein ARO-mCherry, the microneme marker AMA1-mCherry and the rhoptry neck marker AIP-mCherry. (e) Colocalization of PfAAP4-GFP with the rhoptry bulb marker protein ARO-mCherry, the microneme marker AMA1-mCherry, the rhoptry neck marker RON12-mCherry, the dense granules marker EXP2-mCherry and the IMC marker ALV5-mCherry. (f) Structured illumination microscopy (SIM) images of PfAAP4-GFP with the IMC marker ALV5-mCherry during IMC formation. Time points (T) indicated are T1-T3: early schizonts, T4-T6: late schizonts, and T7: free merozoites. Zoom factor: $400 \%$. Scale bars $2 \mu \mathrm{m}$ 
(a)

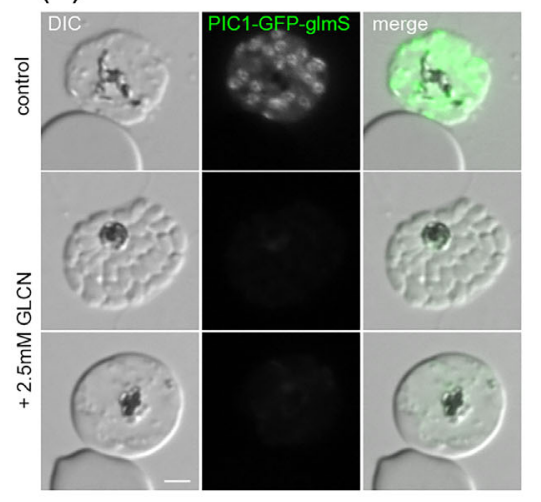

(b)

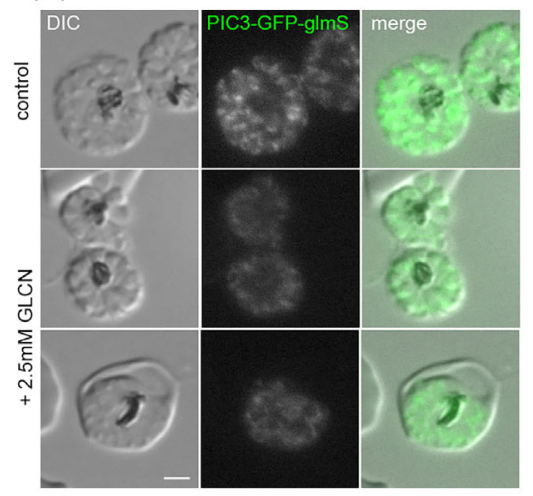

(d)

\section{(c)}

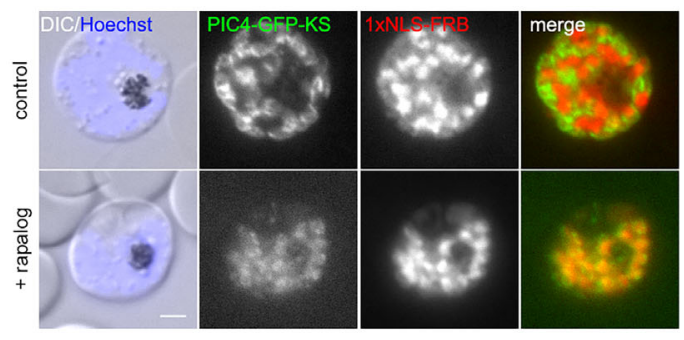

(e)
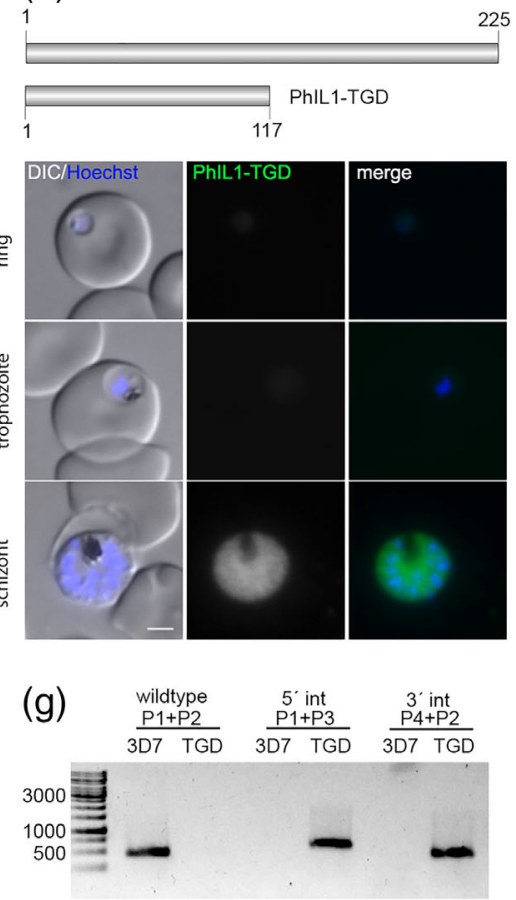

(f)
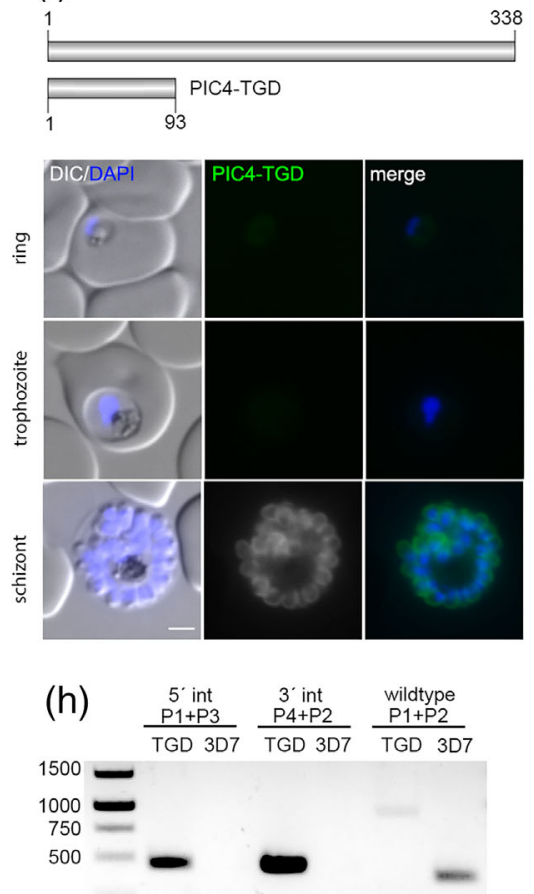

(i)

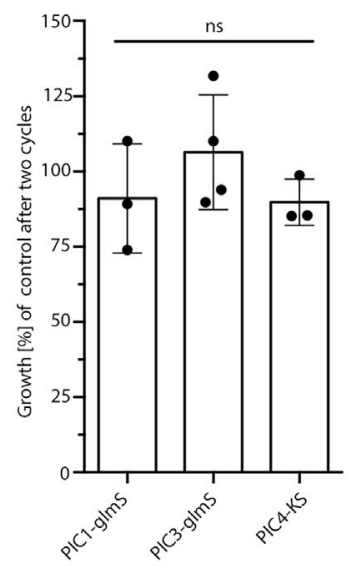

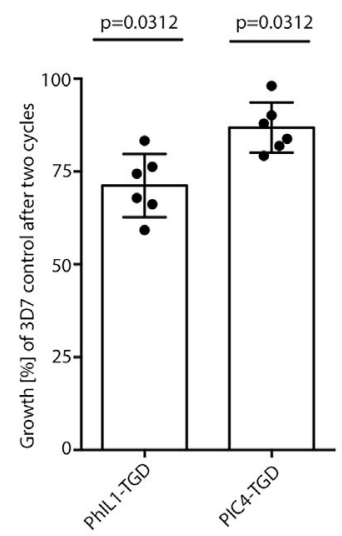

FIG URE 5 Growth phenotypes upon PIC1, PIC3, PIC4 and PhIL1 depletion. (a-d) Conditional knockdown of PIC1 and PIC3 using glucosamine-induced ribozyme activation and knock-sideways of PIC4. Live cell microscopy of (a) PIC1-GFP or (b) PIC3-GFP parasites 36 hr after treatment without (control) or with $2.5 \mathrm{mM}$ glucosamine (GLCN). (c) Live cell microscopy of PIC4-2xFKBP-GFP-2xFKBP parasites expressing the $1 \times$ NLS-FRB-mCherry mislocalizer without (control) or with rapalog (+ rapalog). (d) Growth phenotypes shown as $M \pm S D$ percentage of parasite proliferation compared to untreated parasites after 2 replication cycles. (e-i) Targeted gene disruption of PhIL1 and PIC4 (e,f) Schematic representation (upper panels) of the full-length and truncated versions from PfPhIL1 (e) and PIC4 (f) and microscopic analysis of PhIL1-TGD and PIC4-TGD expressing parasites during asexual blood stage development (stages are indicated). (g,h) PCR analysis of the rendered genomic locus using gDNA of 3D7 (control), PhIL1-TGD (g) and PIC4-TGD parasites (h) confirming targeted gene truncation. Ladder size indicated in base pairs (bp). (i) Growth phenotypes are shown as $M \pm S D$ percentage of growth compared to 3D7 control parasites after 2 parasite replication cycles. Statistical significance in (d) and (i) was determined by Wilcoxon signed-rank test: PIC1-gImS: $p=.5$; PIC3-gImS: $p=.8750$; PIC4-KS: $p=.25$, PhIL1-TGD: $p=.0312$, PIC4-TGD: $p=.0312$ ) Nuclei were stained with Hoechst-33,342. Scale bars $2 \mu \mathrm{m}$ 
microscopy, but did not translate into a significantly decreased parasite proliferation (Figures 5c,d and S5c). Of note, the PIC4-TGD parasite line expressing a truncated version of PIC4 (93 aa instead of full length 338 aa PIC4) shows a $13.1 \%( \pm S D, 6.8 \%)$ reduced growth over two cycles compared to wild-type parasites. This argues for a mild decremental proliferation defect upon PIC4 inactivation. In addition, we also assessed the essentiality of PfPhIL1 for asexual development (Figures 5e,g and S6a,b). The growth rate of PfPhIL1-TGD parasites was reduced by $29 \%( \pm S D, 8.5 \%)$ over two cycles compared to wildtype parasites (Figure $5 \mathrm{~g}$ ).

Taken together, functional inactivation of PIC1, PIC3 or PIC4 had no or a mild measurable growth phenotype. This argues for redundancy of these IMC proteins in asexual proliferation under the given conditions.

\subsection{The Kelch13 compartment is IMC associated in merozoites}

Artemisinin resistance in $P$. falciparum is mainly associated with mutations in the parasite pfkelch13 gene (Ariey et al., 2014; Straimer et al., 2015). Kelch13 has been shown to be involved in endocytosis at the ring stage (Birnbaum et al., 2020) and to be essential for parasite growth (Birnbaum et al., 2017). Endogenously tagged Kelch13 was originally localized to foci in close proximity to the parasite's food vacuole and showed multiple foci in schizonts (Birnbaum et al., 2017). Subsequent work also revealed an association of Kelch13 with $\sim 170 \mathrm{~nm}$ diameter doughnut-shaped structures at the parasite periphery (Yang et al., 2019) and no association with known markers of the secretory system (Birnbaum et al., 2020; Gnädig et al., 2020).

KIC8 (Kelch13 interaction candidate 8), KIC2 (Kelch13 interaction candidate 2) (Birnbaum et al., 2020) and MCA2 (metacaspase-2) are among the top 25 enriched proteins in our PhIL1-based BiolD assay. Vice versa, KIC8, KIC2, MCA2, as well as PhIL1 were found to be enriched in a Kelch13 based DiQ-BiolD experiment (Birnbaum et al., 2020). KIC8 and KIC2 were shown to colocalize with Kelch13 (Birnbaum et al., 2020). To investigate a link between the IMC and the Kelch13 compartment we analysed the list of enriched proteins in our PhIL1-based BiolD approach for other members of the Kelch13 compartment. Indeed, almost all KIC proteins are significantly enriched (Figure 6a,b). In the first elution Kelch13 and all KICs except UBP1 and KIC10 were enriched. In line with this, KIC10 was previously (a)

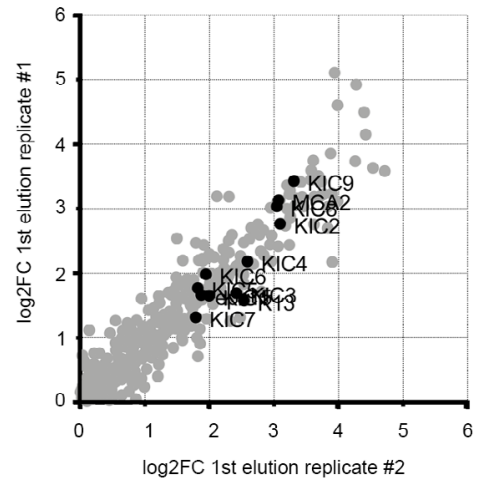

(c)

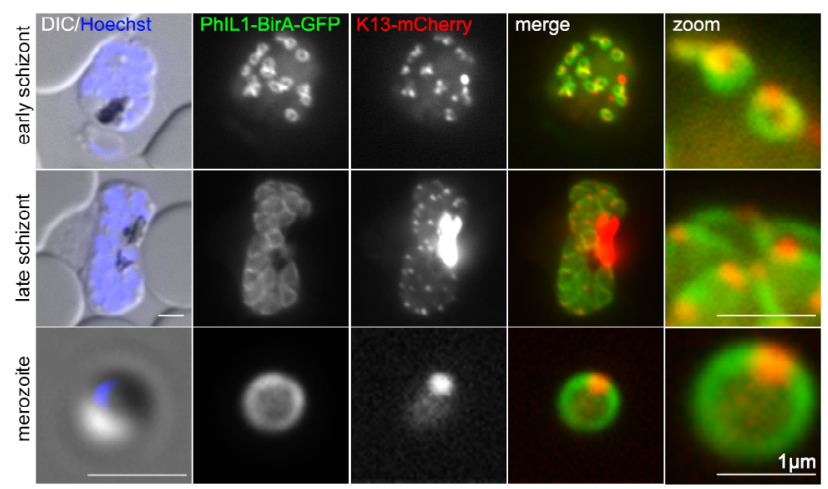

(b)

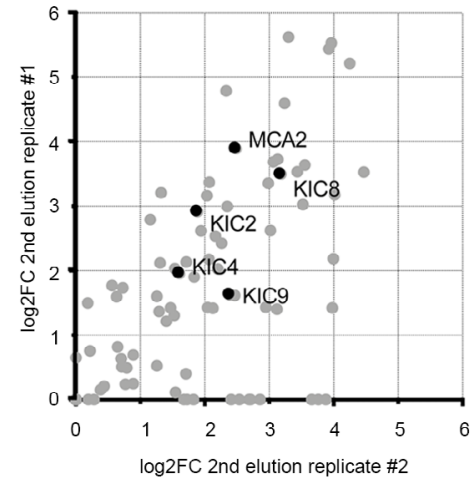

\begin{tabular}{ccc}
\hline gene ID & $\begin{array}{c}\text { mean log2FC } \\
\text { 1st elution }\end{array}$ & $\begin{array}{c}\text { mean log2FC } \\
\text { 2nd elution }\end{array}$ \\
\hline KIC9 & 3.38 & 2.01 \\
MCA2 & 3.11 & 3.19 \\
KIC8 & 3.05 & 3.34 \\
KIC2 & 2.94 & 2.40 \\
KIC4 & 2.40 & 1.78 \\
KIC3 & 2.07 & NA \\
K13 & 2.06 & NA \\
KIC6 & 1.97 & NA \\
KIC1 & 1.83 & -0.07 \\
KIC5 & 1.81 & NA \\
eps15 & 1.78 & NA \\
KIC7 & 1.56 & NA \\
AP2 $\mu$ & 0.82 & NA \\
UBP1 & NA & NA \\
KIC10 & NA & NA \\
\hline
\end{tabular}

(d)

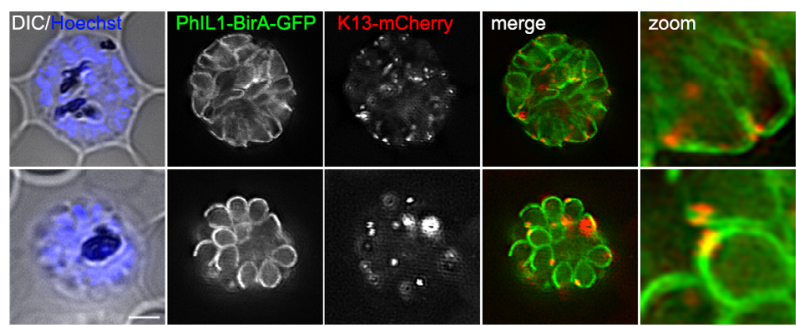

FIG URE 6 The Kelch13 compartment is IMC associated. (a) Scatterplot showing proteins with a log2FC $\geq 0$ in both BiolD replicates (first and second elution). Kelch13 interacting candidates (KIC) (Birnbaum et al., 2020) are highlighted. (b) Mean log2FC values for all KIC proteins in both BioID fractions (c) Localization of Kelch13-mCherry episomally expressed under the control of the nmd3 promoter in the PhIL1-BirA-GFP cell line. Nuclei stained with Hoechst-33,342. Zoom factor: 400\%. Scale bars either $1 \mu \mathrm{m}$ or $2 \mu \mathrm{m}$ as indicated. (d) SIM images of PfPhIL1-BirA-GFP parasites expressing Kelch13-mCherry. Nuclei stained with Hoechst-33,342. Zoom factor: 400\%. Scale bars $2 \mu \mathrm{m}$. NA, not applicable 
identified as not colocalizing with the Kelch13 compartment in schizonts (Birnbaum et al., 2020).

To further probe into this intriguing localization, we first aimed to colocalize KIC8 with PhIL1 by dual tagging of these proteins, unfortunately/but without success. We therefore overexpressed mCherryKelch13, a construct known to colocalize with endogenous Kelch13 (Birnbaum et al., 2020) in the PhIL1-BirA-GFP expressing cell line to enable colocalization. As shown in Figure 6c,d Kelch13 is intimately associated with the nascent IMC at the apical pole during daughter cell formation and in mature schizonts supporting putative PhIL1 interaction. This indicates that either the Kelch13 compartment is intimately associated with the IMC or that Kelch13 compartment proteins are involved in other IMC-related functions in late blood-stage parasites.

\section{DISCUSSION}

In the present study, we used BiolD to probe into the proteome of the IMC in late blood stages of $P$. falciparum. Within the top 58 enriched proteins that show a mean $\log _{2}$ fold change $>1$ in the second elution steps are 12 known IMC proteins (PhIL1 (Parkyn Schneider et al., 2017; Saini et al., 2017), CINCH (Rudlaff et al., 2019), GAPM1-3 (Bullen et al., 2009; Kono et al., 2012), ALV4/IMC1g (Hu et al., 2010), ALV5/IMC1c (Hu et al., 2010), IMC1f (Al-Khattaf, Tremp, \& Dessens, 2015), GAP45 (Baum et al., 2006), PF3D7_1345600 (Kono et al., 2012), BCP1 (Rudlaff et al., 2019) and ISP3 (Kono et al., 2012)) comprising approximately one quarter of all known IMC proteins (Ferreira et al., 2021), while another nine IMC proteins or homologues of $T$. gondii IMC proteins are among the proteins showing a mean $\log 2 \mathrm{FC}>1$ in the first elutions (IMC1m (AIKhattaf et al., 2015; Gao et al., 2018), ALV2 (Kono et al., 2012; Tremp, Al-Khattaf, \& Dessens, 2014), ALV1 (Al-Khattaf, Tremp, El-Houderi, \& Dessens, 2017; Khater, Sinden, \& Dessens, 2004), PfIMC32 (Torres, Pasquarelli, Back, Moon, \& Bradley, 2021), PfISC1 (Chen et al., 2015), ALV7 (Gao et al., 2018; Kono et al., 2012), Coronin (Bane et al., 2016), DHHC1 (Wetzel et al., 2015) and PIP1 (Parkyn Schneider et al., 2017). Additionally, the BiolD-based protein identification revealed with PPP8 a protein, that was previously identified using a $\mathrm{CINCH}$ immunoprecipitation (IP) approach (Rudlaff et al., 2019). Of note, PIP2 and PIP3 (PhIL1 interacting proteins 2 and 3) identified in gametocytes (Parkyn Schneider et al., 2017) were not among the hits, which might indicate different IMC composition in schizonts and gametocytes.

We validated nine candidates identified by our BiolD approach and present six novel $P$. falciparum IMC proteins that we named PIC1-6. PIC2 (PF3D7_0822900) has been previously identified in IP experiments using PfMyoA (Green et al., 2017) or PfPhIL1 (Parkyn Schneider et al., 2017) / PbPhIL1 (Saini et al., 2017) as bait, while PIC5 (PF3D7_1310700), which contains a predicted putative RNA binding domain (Mitchell et al., 2019), was present in IP experiments of PbPhIL1 (Saini et al., 2017) and PfCINCH (Rudlaff et al., 2019).

PIC1 and PIC6 contain a predicted (Almagro Armenteros et al., 2019) N-terminal signal peptide (Figure 2a,e). This $\mathrm{N}$-terminal signature is rather unusual for IMC proteins and only the known IMC proteins NIPA (PF3D7_0522600) and DHHC9 (PF3D7_1115900) also show this feature. With PIC1, PIC3 and PIC6 three proteins contain at least one predicted (Sonnhammer, von Heijne, \& Krogh, 1998) transmembrane domain (Figure 2a,d,e). Single putative transmembrane domains are known for the IMC protein G2 (PF3D7_0929600), while multiple transmembrane domains are also predicted for GAPM1-3, DHHC1-3 and DHHC9, BTP1/BTP2, NIPA and GAP40/GAP50.

Functional inactivation of PIC1, PIC3 or PIC4 by either ribozymemediated mRNA degradation or knock-sideways revealed no growth phenotype. While PIC1 and PIC3 have been classified as dispensable in a genome-wide mutagenesis screen (Zhang et al., 2018), PIC4 is predicted to be essential. Although ribozyme-mediated protein downregulation was substantial and mis-localization was efficient (Figure S5), the residual amount of these proteins still present might be sufficient to mediate normal IMC function under the given growth conditions. However, as the gene encoding PIC4 could be disrupted, which resulted only in a minor growth reduction, this is not a likely explanation for this candidate. Even though the truncated PIC4 fragment shows still partial IMC localization it can be assumed that PIC4 is largely dispensable for intraerythrocytic development at least under the applied in vitro conditions.

Ribozyme-mediated knockdown of PfPhIL1 leads to no significant growth defect in asexual parasite proliferation (Parkyn Schneider et al., 2017). We also probed into the essentiality of PfPhIL1 itself and the successful generation of a PfPhIL1-TGD parasite line expressing truncated and cytosolic PfPhIL1. Parasites are viable but show a $29 \%$ reduced growth rate over two cycles indicating a small fitness loss. A reduced fitness was also reported upon knockout of TgPhIL1 in $T$. gondii (Barkhuff et al., 2011) .

Besides novel IMC proteins the BioID list contains at least three putative apical annuli proteins of $P$. falciparum (PfAAP2, PfAAP4 and PfAAP6), for which endogenous GFP-tagging revealed an apical localization but no colocalization with the apical organelles. Apical annuli or peripheral annuli are structures that so far have only been described in $T$. gondii and were discovered by localization of TgCEN2 (Hu et al., 2006) and TgAAP1 (Suvorova et al., 2015). They consist of five to six rings at the lower edge of the apical cap. While the function of the apical annuli remains unresolved, they have been linked with the IMC, more precisely with the T. gondii ISP sub-compartment (Beck et al., 2010). Several IMC proteins (including TgPhIL1) were enriched in a TgAAP4 BiolD (Engelberg et al., 2019) and TgAAP4 has been previously identified in a BiolD experiment using the alveolar suture component TgISC4 (Chen et al., 2017) as bait. Although their function is unknown, it has been speculated that apical annuli may serve a pore function facilitating the efficient exchange of nutrients and waste products across the IMC or may serve as a signalling platform (Engelberg et al., 2019). So far eight proteins of T. gondii have been shown to localize to the annuli (TgAAP1-5 (Engelberg et al., 2019), TgAAMT (Engelberg et al., 2019), TgCEN2 (Hu et al., 2006; Lentini et al., 2019; Leung et al., 2019) and TgPI-PLC (Hortua Triana et al., 2018)). 
The absence of three of five aap genes-present in $T$. gondii (Engelberg et al., 2019)-in the Plasmodium genome and the lack of a homologue of PfAAP6 in T. gondii raises the question how conserved the proteome and the function of the annuli is between these species. Further studies are needed to address these questions.

Of note, apical annuli proteins are expressed in multiple stages of the $P$. falciparum life cycle, as indicated by high mRNA expression of pfaap4 in schizonts, merozoites (Wichers et al., 2019), gametocytes (López-Barragán et al., 2011), ookinetes (López-Barragán et al., 2011) and sporozoites (Zanghì et al., 2018) even though we did not observe a detectable signal of PfAAP4-GFP, PfAAP6-GFP or PfAAP2-GFP in gametocytes (Figure S3).

Additionally, we identified PfAAMT (PF3D7_1455200) as a homologue of TgAAMT (Engelberg et al., 2019), indicating that the list might contain additional $P$. falciparum apical annuli proteins. Together with recent reports on conserved proteins of the conoid structure (Bertiaux et al., 2021; Koreny et al., 2021; Leung et al., 2020; Wall et al., 2016) the presence of apical annuli in $P$. falciparum may indicate a similar and conserved organisation of the apical pole in Apicomplexan parasites.

An additional, interesting finding of our PhIL1-based BiolD assay was the significant enrichment of Kelch13 interacting candidates (KICs). This is in agreement with the Kelch13 based BiolD approach (Birnbaum et al., 2020), which identified PhIL1, as well as other IMC proteins such as ALV4/IMC1g, ALV5/IMC1C, PF3D7_1345600, ISP3 and GAPM2 to be enriched although at a lower level than other KICs. We show an intimate association between the Kelch13 compartment with the nascent IMC at the apical pole during daughter cell formation (Figure 6c,d). Kelch13 has been recently suggested to localize to cytostome-like structures at the parasite periphery in schizonts (Yang et al., 2019). The function of the Kelch13 compartment and cytostome-like structures in late schizont and merozoites remains to be elucidated. It could either represent a re-purposing of these endocytosis-linked structures (Spielmann, Gras, Sabitzki, \& Meissner, 2020) for host cell invasion and the establishment of the parasite in a new host cell or serve an endocytosis-related function in schizonts, as it has been recently shown that schizonts still appear to endocytose host cell haemoglobin (Bisio et al., 2020).

\section{4 | EXPERIMENTAL PROCEDURES}

\section{1 | P. falciparum culture}

The $P$. falciparum clone 3D7 (Walliker et al., 1987) was cultured at a haematocrit of $5 \%$ in human $\mathrm{O}^{+}$erythrocytes according to standard procedures (Trager \& Jensen, 1997). To maintain synchronized parasites, cultures were treated with $5 \%$ sorbitol (Lambros \& Vanderberg, 1979). The PKG-inhibitor compound 2 was used at a final concentration of $1 \mu \mathrm{M}$ to arrest parasite egress before exoneme/microneme secretion as previously described (Collins et al., 2013).

\section{2 | Cloning of DNA constructs}

For generating the PhIL1-BirA-GFP construct, a homology region of 669 bp was amplified using 3D7 gDNA and cloned into pSLI-TGD (Birnbaum et al., 2017) via Notl and Avrll restriction sites, next the BirA sequence was amplified from pSP-GFP-BirA (Khosh-Naucke et al., 2018) and inserted via the Avrll/Mlul restriction site, resulting in pSLI-PhIL1-BirA-GFP. For endogenous tagging using the SLI system (Birnbaum et al., 2017), a homology region of $426-1087 \mathrm{bp}$ (1001 bp for Pf3D7_1229300, $1087 \mathrm{bp}$ for Pf3D7_0822900, $1056 \mathrm{bp}$ for Pf3D7_ 0415800, $866 \mathrm{bp}$ for Pf3D7_0623800, $1028 \mathrm{bp}$ for Pf3D7_020 3000, 1041 bp for Pf3D7_0508900, 917 bp for Pf3D7_1318700, 426 bp for Pł3D7_1310700 and 1038 bp for Pf3D7_1312800 respectively) was amplified using 3D7 gDNA and cloned into pSLI-GFP-glmS (Burda et al., 2020) (derived from pSLI-GFP (Birnbaum et al., 2017)) using the Notl/Mlul restriction site. For PF3D7_0308300, a 650 bp homology region was amplified from 3D7 gDNA and cloned into pSLI-sandwich (Birnbaum et al., 2017) via Notl and Avrll restriction sites.

For targeted gene disruption (TGD) a homology region of $348 \mathrm{bp}$ for PfPhIL1 or 273 bp for PF3D7_0308300 were amplified from 3D7 gDNA or synthesized by Life Technologies (Darmstadt, Germany) and cloned into pSLI-TGD using the Notl/Mlul restriction site (Birnbaum et al., 2017).

For colocalization experiments, the full length sequence of organellar marker genes for micronemes (ama1 Pf3D7_1133400) (Healer et al., 2002; Peterson et al., 1989), rhoptry neck (aip, Pf3D7_1136700; ron12 Pf3D7_1017100) (Geiger et al., 2020; Ito et al., 2019; Knuepfer et al., 2014), IMC (imc1c/alv5, Pf3D7_1003600) (Hu et al., 2010) were amplified from 3D7 cDNA and for dense granules (exp2, PF3D7_1471100) (Bullen et al., 2012) from the plasmid pEXP2rec (Mesén-Ramírez et al., 2019) and cloned into pARLama1-ARO-mCherry-BSD (Cabrera et al., 2012) using the AvrlI/Kpnl restriction site or in pARL-ama1-ARO-mCherry-yDHODH (derived from pARL-ama1-ARO-mCherry-BSD (Cabrera et al., 2012)).

Additionally, the plasmids pBcamR-alv5-mCherry (Kono et al., 2012), pARL-ARO-mCherry-BSD (Cabrera et al., 2012) were used for colocalization experiments. Oligonucleotides used for cloning are listed in Table S2.

\section{3 $\quad$ Transfection of $P$. falciparum}

For transfection, Percoll-purified (Rivadeneira, Wasserman, \& Espinal, 1983) parasites at late schizont stage were transfected with $50 \mu \mathrm{g}$ plasmid DNA using Amaxa Nucleofector 2b (Lonza, Switzerland) as previously described (Moon et al., 2013). Transfectants were selected using either 4 nM WR99210 (Jacobus Pharmaceuticals), $0.9 \mu \mathrm{M}$ DSM1 (BEI Resources) or $2 \mu \mathrm{g} / \mathrm{ml}$ blasticidin S (Life Technologies, USA). To select for parasites carrying the genomic modification via the SLI system (Birnbaum et al., 2017), G418 (ThermoFisher, USA) at a final concentration of $400 \mu \mathrm{g} / \mathrm{ml}$ was added to a culture with $5 \%$ parasitemia. The selection process and integration test were performed as previously described (Birnbaum et al., 2017). 


\section{4 | Imaging and immunofluorescence assay (IFA)}

Fluorescence images were captured using a Zeiss Axioskop 2plus microscope with a Hamamatsu Digital camera (Model C4742-95) or a Leica D6B fluorescence microscope equipped with a Leica DFC9000 GT camera and a Leica Plan Apochromat $100 \times / 1.4$ oil objective. Microscopy of live parasite-infected erythrocytes was performed as previously described (Grüring \& Spielmann, 2012). Briefly, parasites were incubated in a standard culture medium with $1 \mu \mathrm{g} / \mathrm{ml}$ Hoechst-33,342 (Invitrogen) for 15 mins at $37^{\circ} \mathrm{C}$ prior to imaging. $5.4 \mu \mathrm{l}$ of infected erythrocytes were added on a glass slide and covered with a coverslip. IFAs were performed as described previously (Bachmann et al., 2015). Mouse anti-GFP antibodies (Roche) were used at a dilution of 1:1,000, goat anti-mouse antibodies coupled to Alexa Fluor® 488 at 1:2,000 and streptavidin coupled to Alexa Fluor® 595 (Invitrogen) at 1:4,000. Nuclei were stained with $1 \mu \mathrm{g} / \mathrm{ml}$ Hoechst-33,342 (Invitrogen). Airyscan confocal imaging in superresolution mode was carried out using a Zeiss Airyscan LSM 880 microscope equipped with 405-nm, 488-nm and 594-nm laser lines and a 63x Plan APO NA 1.4 oil immersion objective.

For generation of SIM images, parasites were stained with $2 \mu \mathrm{g} / \mathrm{ml}$ DAPI in medium for $20 \mathrm{~min}$ at $37^{\circ} \mathrm{C}$. They were then placed on a microscope slide, covered with a coverslip and immediately imaged on a Zeiss Elyra microscope equipped with a Plan-Apochromat $100 x / 1.46$ oil objective. Reconstruction of SIM images was performed in ZEN 2.3 Black software using default settings.

Images were processed using Fiji (Schindelin et al., 2012) and Adobe ${ }^{\circledR}$ Photoshop ${ }^{\circledR}$ CC 2019 was used for display purposes only.

\subsection{Western blot analysis}

Immunoblots were performed using saponin-lysed, infected erythrocytes material. Proteins were separated on a $4-12 \%$ Bis-Tris (abcam) SDSPAGE and transferred to nitrocellulose membranes (Licor) using a semi-dry electroblotting system (Thermo Fisher Scientific Inc.). The membranes were blocked with 3\% BSA in TBS containing 0.05\% Tween-20 (TBST) for $2 \mathrm{hr}$ and then probed with rabbit anti-BiP (1:2,000) (Struck et al., 2005) primary antibodies in TBST at $4^{\circ} \mathrm{C}$ overnight. After washing three times with TBST for 10 mins, the membranes were incubated with goat anti-rabbit lgG coupled to IRDye ${ }^{\circledR} 680 \mathrm{CW}$ and streptavidin coupled to IRDye ${ }^{\circledR} 800 \mathrm{CW}$ (LI-COR Biosciences) at 1:10,000 in $5 \mathrm{ml} 3 \%$ BSA/TBST for $1 \mathrm{hr}$ at room temperature. After washing the membrane three times with TBST for $10 \mathrm{~min}$, fluorescent signals were visualized using Odyssey Fc Imager by LI-COR Biosciences.

Western blot analysis of the PfPhil1-BirA-GFP expressing cell were done using a slightly different protocol (Bachmann et al., 2015; Heiber \& Spielmann, 2014): Proteins separated on a $12 \%$ SDS-Page were transferred to a nitrocellulose membrane using a Trans-Blot device (Bio-Rad) according to the manufacturer's instructions. The membranes were blocked with 3\% skim milk in TBS for 30 mins and then probed with mouse anti-GFP (1:1,000, Roche) or rabbit anti-aldolase (Mesén-Ramírez et al., 2016) (1:2,000). The chemiluminescent signal of the horseradish peroxidase-coupled secondary antibodies (Dianova) was visualized using a Chemi Doc XRS imaging system (Bio-Rad) and processed with Image Lab 5.2 software (Bio-Rad).

\subsection{BiolD and mass spectrometry analysis}

The protocol for proximity-dependent biotin identification (BiolD) (Roux et al., 2012) in P. falciparum was adapted from previously published assays (Geiger et al., 2020; Khosh-Naucke et al., 2018) and mass spectroscopy analysis was performed as described (Geiger et al., 2020). Briefly, $100 \mathrm{ml}$ of highly synchronous PfPhIL1-BirA-GFP or 3D7 parasites at a parasitemia of 7 to $10 \%$ were grown until $40 \mathrm{hpi}$. Then the cultures were grown in culture media supplemented with $150 \mu \mathrm{M}$ biotin (Sigma-Aldrich) and compound 2 was added for $8 \mathrm{hr}$. Erythrocytes were lysed with $0.03 \%$ saponin and the isolated parasites were washed twice with PBS, taken up in lysis buffer $(50 \mathrm{mM}$ Tris- $\mathrm{HCl}$ pH 7.5, $500 \mathrm{mM} \mathrm{NaCl}, 1 \mathrm{mM} \mathrm{DTT}, 1 \mathrm{mM}$ PMSF, 2x protease inhibitor mix, $1 \%$ Triton) and frozen at $-80^{\circ} \mathrm{C}$. Three freeze-thaw cycles were performed; the samples were centrifuged at $25,000 \mathrm{~g}$ for 60 mins at $4^{\circ} \mathrm{C}$ and the supernatant was stored at $-80^{\circ} \mathrm{C}$. For purification of biotinylated proteins, $50 \mu \mathrm{l}$ streptavidin sepharose (GE Healthcare) was added to the lysate and incubated overnight with end-over-end rotation at $4^{\circ} \mathrm{C}$. The beads were washed twice in lysis buffer, once in $\mathrm{dH}_{2} \mathrm{O}$, twice in Tris- $\mathrm{HCl}(\mathrm{pH}$ 8.5) and three times in $100 \mathrm{mM}$ triethylammonium bicarbonate buffer (TEAB) pH 7.5 (SigmaAldrich). The washed beads were resuspended in $200 \mu \mathrm{l} 50 \mathrm{mM}$ ammonium bicarbonate $(\mathrm{pH} 8.3$ ) and on-bead trypsin digest (rolling with $1 \mu \mathrm{g}$ of trypsin (Roche) for $16 \mathrm{hr}$ at $37^{\circ} \mathrm{C}$ followed by a second trypsin digest with $0.5 \mu \mathrm{g}$ trypsin for $2 \mathrm{hr}$ ) was performed. Next the samples were centrifuged at 2,000g for 5 mins, resuspended in $2 \times 150 \mu 50 \mathrm{mM}$ ammonium bicarbonate $(\mathrm{pH}$ 8.3, “first elution: Ambic"), transferred to and collected in a spin column (Pierce Spin Columns with Snap Cap, Thermo Scientific) placed in a low binding tube (Low Protein Binding Microcentrifuge tubes, Thermo Scientific). Subsequently, the left-over biotinylated peptides were eluted from the beads by $2 \times 150 \mu \mathrm{l} 80 \%$ acetonitrile and $20 \%$ trifluoroacetic acid ("second elution: ACN"). Then, the samples were dried using SpeedVac (Thermo Fisher Scientific) and stored at $-20^{\circ} \mathrm{C}$.

Dried peptides were sent to the Proteomics Core Facility at EMBL Heidelberg. Peptides were dissolved in 1\% formic acid/4\% acetonitrile, sonicated in the ultrasonic bath for 5 mins and desalted using an OASIS ${ }^{\circledR}$ HLB $\mu$ Elution Plate (Waters). Cleaned peptides were dissolved in $50 \mathrm{mM}$ Hepes pH 8.5 and labelled with TMT6plex Isobaric Label Reagent (ThermoFisher) according to the manufacturer's instructions. After labelling, samples were pooled and purified from unreacted TMT label using OASIS ${ }^{\circledR}$ HLB $\mu$ Elution Plate (Waters). An UltiMate 3,000 RSLC nano LC system (Dionex) fitted with a trapping cartridge ( $\mu$-Precolumn C18 PepMap 100, $5 \mu \mathrm{m}, 300 \mu \mathrm{m}$ i.d. $\times 5 \mathrm{~mm}$, $100 \AA$ ) and an analytical column (nanoEase ${ }^{\mathrm{TM}} \mathrm{M} / \mathrm{Z}$ HSS T3 column $75 \mu \mathrm{m} \times 250 \mathrm{~mm}$ C18, $1.8 \mu \mathrm{m}, 100 \AA$ A , Waters). Trapping was carried out with a constant flow of solvent $A(0.1 \%$ formic acid in water) at $30 \mu \mathrm{l} / \mathrm{min}$ onto the trapping column for 6 mins. Subsequently, peptides were eluted via the analytical column with a constant flow of 
$0.3 \mu \mathrm{l} / \mathrm{min}$ with an increasing percentage of solvent $\mathrm{B}(0.1 \%$ formic acid in acetonitrile) from 2 to $4 \%$ in $4 \mathrm{~min}$, from 4 to $8 \%$ in $2 \mathrm{~min}$, then 8 to $28 \%$ for a further $37 \mathrm{~min}$, and finally from 28 to $40 \%$ in another $9 \mathrm{~min}$. The outlet of the analytical column was coupled directly to a QExactive plus (Thermo) mass spectrometer using the proxeon nanoflow source in positive ion mode. The peptides were introduced into the QExactive plus via a Pico-Tip Emitter $360 \mu \mathrm{m}$ OD $\times 20 \mu \mathrm{m}$ ID; $10 \mu \mathrm{m}$ tip (New Objective) and an applied spray voltage of $2.1 \mathrm{kV}$. The capillary temperature was set at $275^{\circ} \mathrm{C}$. Full mass scan was acquired with mass range $375-1,200 \mathrm{~m} / \mathrm{z}$ in profile mode with a resolution of 70,000 . The filling time was set at a maximum of $10 \mathrm{~ms}$ with a limitation of $3 \times 10^{6}$ ions. Data-dependent acquisition (DDA) was performed with the resolution of the Orbitrap set to 17,500, with a fill time of $50 \mathrm{~ms}$ and a limitation of $2 \times 10^{5}$ ions. A normalized collision energy of 32 was applied. Dynamic exclusion time of $30 \mathrm{~s}$ was used. The peptide match algorithm was set to "preferred" and charge exclusion "unassigned," charge states 1, 5-8 were excluded. MS2 data were acquired in profile mode. IsobarQuant (Franken et al., 2015) and Mascot (v2.2.07) were used to process the acquired data, which was searched against a Uniprot P. falciparum (UP000001450) proteome database containing common contaminants and reversed sequences. The following modifications were included in the search parameters: Carbamidomethyl (C) and TMT10 (K) (fixed modification), Acetyl (Protein N-term), Oxidation (M) and TMT10 (N-term) (variable modifications). For the full scan (MS1) a mass error tolerance of $10 \mathrm{ppm}$ and for MS/MS (MS2) spectra of $0.02 \mathrm{Da}$ was set. Further parameters were set: trypsin as protease with an allowance of maximum two missed cleavages: a minimum peptide length of seven amino acids; at least two unique peptides were required for protein identification. The false discovery rate on peptide and protein level was set to 0.01 .

The mass spectrometry proteomics raw data have been deposited to the ProteomeXchange Consortium via the PRIDE (Vizcaíno et al., 2016) repository with the dataset identifier PXD024237.

\section{7 | Growth assay}

For growth assays of PhIL1-TGD a flow cytometry assay adapted from previously published assays (Jonscher et al., 2019; Malleret et al., 2011) was performed to measure parasite growth over 5 days. To obtain highly synchronous parasite cultures late schizonts were isolated by percoll gradient (Rivadeneira et al., 1983) and cultured with fresh erythrocytes on a shaker for $4 \mathrm{hr}$. Afterwards sorbitol synchronisation (Lambros \& Vanderberg, 1979) was applied to remove remaining schizonts resulting in a highly synchronous ring-stage parasite culture with a 4-hr age window. Next the parasitemia was determined by flow cytometry and the culture diluted to $0.1 \%$ parasitemia. Each day parasite cultures were resuspended and $20 \mu$ samples were transferred to an Eppendorf tube. $80 \mu \mathrm{l}$ RPMI containing Hoechst33,342 or SYBR green and dihydroethidium (DHE) was added to obtain final concentrations of 5 and $4.5 \mu \mathrm{g} / \mathrm{ml}$, respectively. Samples were incubated for $20 \mathrm{~min}$ (protected from UV light) at room temperature, and parasitemia was determined using an LSRII flow cytometer or an ACEA NovoCyte flow cytometer by counting 100000 events using the FACSDiva software (BD Biosciences).

\section{8 | GlmS-based knockdown}

GlmS-based knockdown assay was adapted from previously published assays (Burda et al., 2020; Prommana et al., 2013). To induce knockdown, highly synchronous early rings stage parasites were split into two dishes and $2.5 \mathrm{mM}$ glucosamine was added to one of them and parasite growth was measured by flow cytometry over 5 days as described above. As an additional control, the same amount of glucosamine was also added to 3D7 wildtype parasites. For all analyses, medium was changed daily, and fresh glucosamine was added every day.

Knockdown was quantified by fluorescence live-cell microscopy using schizonts $36 \mathrm{hr}$ post glucosamine treatment. Parasites with similar sizes were imaged, and fluorescence was captured with the same acquisition settings to obtain comparable measurements of the fluorescence intensity. Fluorescence intensity (integrated density) was measured with Fiji (Schindelin et al., 2012), and background was subtracted in each image. The data was visualized with Graph Pad Prism version 8.

\subsection{Conditional inactivation via knock-sideways}

The knock-sideways approach was performed as described previously (Birnbaum et al., 2017). The PF3D7_0308300-2xFKBP-GFP-2xFKBP schizonts were isolated using a percoll gradient (Rivadeneira et al., 1983) and incubated for $4 \mathrm{hr}$ with fresh erythrocytes. Next, parasites were treated with $5 \%$ sorbitol (Lambros \& Vanderberg, 1979) to obtain a culture containing rings of a stage window of zero to $4 \mathrm{hr}$ after invasion. The culture was split into two 2-ml cultures of which one was supplemented with $250 \mathrm{nM}$ rapalog (Clontech). Parasite growth was determined via flow cytometry over 5 days as described above. Mislocalization of PF3D7_0308300-2xFKBP-GFP-2xFKBP into the nucleus was confirmed by live-cell microscopy $36 \mathrm{hr}$ after rapalog addition.

\subsection{0 | Protein schematics}

Schematic protein representations were designed using IBS (Liu et al., 2015), predicted protein domains were obtained from plasmoDB (Aurrecoechea et al., 2009) interfered from Interpro (Mitchell et al., 2019) and TMHMM (Sonnhammer et al., 1998).

\section{ACKNOWLEDGEMENTS}

The authors thank Michael Geiger for cloning of pARLama1_AIPmCherry, Jacobus Pharmaceuticals for WR99210, the Proteomics Core Facility at EMBL Heidelberg for support with mass spectrometry sample preparation, measurements and data analysis. 
Microscopy experiments were supported by the Advanced Light and Fluorescence Microscopy facility at the CSSB, in particular Roland Thünauer. The following reagent was obtained through $\mathrm{BEI}$ Resources, NIAID, NIH: DSM1, MRA-1161. This work is supported in part by the German Research Foundation (DFG) grant BA 5213/3-1 (A.B., J.S.W.), the Boehringer Ingelheim Foundation (J.W., C.L.), Partnership of Universität Hamburg and DESY (PIER) project ID PIF2018-87 (J.S., C.L., T.W.G.), Landesforschungsförderung Hamburg LFF FV-69 (M.F., T.W.G.) and CSSB Seed grant KIF 2019/002 (T.W.G.), M.S. and J.K. were supported by the Jürgen Manchot Stiftung. The funders had no role in study design, data collection and analysis, decision to publish, or preparation of the manuscript. Open Access funding enabled and organized by Projekt DEAL.

\section{CONFLICT OF INTEREST}

The authors declare no conflict of interest.

\section{AUTHOR CONTRIBUTIONS}

Conceptualization: Tim W. Gilberger; Methodology: Jan Stephan Wichers, Juliane Wunderlich, Dorothee Heincke, Samuel Pazicky, Jan Strauss, Paul-Christian Burda, Tobias Spielmann, Christian Löw, Michael Filarsky, Anna Bachmann, Tim W. Gilberger; Validation: Jan Stephan Wichers, Juliane Wunderlich, Dorothee Heincke, Samuel Pazicky, Jan Strauss, Marius Schmitt, Jessica Kimmel, Louisa Wilcke, Sarah Scharf, Heidrun von Thien, Paul-Christian Burda; Formal Analysis: Jan Stephan Wichers, Juliane Wunderlich, Dorothee Heincke, Samuel Pazicky, Jan Strauss, Tim W. Gilberger; Writing original manuscript: Jan Stephan Wichers, Juliane Wunderlich, Tim W. Gilberger; Review \& Editing: Jan Stephan Wichers, Tobias Spielmann, Anna Bachmann, Tim W. Gilberger; Visualization: Jan Stephan Wichers, Juliane Wunderlich, Jan Strauss, Tim W. Gilberger; Funding Acquisition: Jan Strauss, Christian Löw, Michael Filarsky, Anna Bachmann, Tim W. Gilberger; Resources: Christian Löw, Tim W. Gilberger; Project Administration: Tobias Spielmann, Christian Löw, Michael Filarsky, Anna Bachmann, Tim W. Gilberger; Supervision: Tobias Spielmann, Christian Löw, Anna Bachmann, Tim W. Gilberger. All authors read and approved the manuscript.

\section{DATA AVAILABILITY STATEMENT}

Data of this study are available at ProteomeXchange Consortium via the PRIDE with the dataset identifier PXD024237.

\section{ORCID}

Jan Stephan Wichers (D) https://orcid.org/0000-0002-0599-1742

Juliane Wunderlich (D) https://orcid.org/0000-0002-5818-5488

Dorothee Heincke (D) https://orcid.org/0000-0002-7169-5239

Samuel Pazicky (D) https://orcid.org/0000-0002-4674-9784

Jan Strauss (iD https://orcid.org/0000-0002-6208-791X

Marius Schmitt (D) https://orcid.org/0000-0002-4103-4026

Jessica Kimmel (D) https://orcid.org/0000-0001-9882-235X

Louisa Wilcke (D) https://orcid.org/0000-0002-3572-272X

Sarah Scharf (D) https://orcid.org/0000-0001-7038-1978

Paul-Christian Burda (D) https://orcid.org/0000-0003-0461-4352
Tobias Spielmann (D) https://orcid.org/0000-0002-3968-4601

Christian Löw (D) https://orcid.org/0000-0003-0764-7483

Michael Filarsky (D) https://orcid.org/0000-0003-3514-1711

Anna Bachmann (D) https://orcid.org/0000-0001-8397-7308

Tim W. Gilberger (D) https://orcid.org/0000-0002-7965-8272

\section{REFERENCES}

Abdi, A., Eschenlauer, S., Reininger, L., \& Doerig, C. (2010). SAM domaindependent activity of PfTKL3, an essential tyrosine kinase-like kinase of the human malaria parasite Plasmodium falciparum. Cellular and Molecular Life Sciences, 67, 3355-3369.

Al-Khattaf, F. S., Tremp, A. Z., \& Dessens, J. T. (2015). Plasmodium alveolins possess distinct but structurally and functionally related multi-repeat domains. Parasitology Research, 114, 631-639.

Al-Khattaf, F. S., Tremp, A. Z., El-Houderi, A., \& Dessens, J. T. (2017). The plasmodium alveolin IMC1a is stabilised by its terminal cysteine motifs and facilitates sporozoite morphogenesis and infectivity in a dosedependent manner. Molecular and Biochemical Parasitology, 211, 48-56.

Allen, R. D. (1971). Fine structure of membranous and microfibrillar systems in the cortex of Paramecium caudatum. The Journal of Cell Biology, 49, 1-20.

Almagro Armenteros J. J., Tsirigos K. D., Sønderby C. K., Petersen T. N., Winther O., Brunak S., ... Nielsen H. (2019). SignalP 5.0 improves signal peptide predictions using deep neural networks. Nature Biotechnology, 37(4), 420-423. https://doi.org/10.1038/s41587-019-0036-z.

Anderson-White, B. R., Ivey, F. D., Cheng, K., Szatanek, T., Lorestani, A., Beckers, C. J., ... Gubbels, M. J. (2011). A family of intermediate filament-like proteins is sequentially assembled into the cytoskeleton of toxoplasma gondii. Cellular Microbiology, 13, 18-31.

Ariey, F., Witkowski, B., Amaratunga, C., Beghain, J., Langlois, A. C., Khim, N., ... Ménard, D. (2014). A molecular marker of artemisinin-resistant Plasmodium falciparum malaria. Nature, 505, 50-55.

Aurrecoechea, C., Brestelli, J., Brunk, B. P., Dommer, J., Fischer, S., Gajria, B., ... Wang, H. (2009). PlasmoDB: A functional genomic database for malaria parasites. Nucleic Acids Research, 37, D539-D543.

Bachmann, A., Scholz, J. A. M., Janßen, M., Klinkert, M.-Q., Tannich, E., Bruchhaus, I., \& Petter, M. (2015). A comparative study of the localization and membrane topology of members of the RIFIN, STEVOR and PfMC-2TM protein families in Plasmodium falciparum-infected erythrocytes. Malaria Journal, 14, 274.

Bane, K. S., Lepper, S., Kehrer, J., Sattler, J. M., Singer, M., Reinig, M., ... Frischknecht, F. (2016). The Actin filament-binding protein Coronin regulates motility in Plasmodium sporozoites. PLoS Pathogens, 12, e1005710.

Bannister, L. H., Hopkins, J. M., Fowler, R. E., Krishna, S., \& Mitchell, G. H. (2000). A brief illustrated guide to the ultrastructure of Plasmodium falciparum asexual blood stages. Parasitology Today, 16, 427-433.

Barkhuff, W. D., Gilk, S. D., Whitmarsh, R., Tilley, L. D., Hunter, C., \& Ward, G. E. (2011). Targeted disruption of TgPhiL1 in toxoplasma gondii results in altered parasite morphology and fitness. PLoS One, 6, e23977.

Barylyuk, K., Koreny, L., Ke, H., Butterworth, S., Crook, O. M., Lassadi, I., ... Waller, R. F. (2020). A comprehensive subcellular atlas of the toxoplasma proteome via hyperLOPIT provides spatial context for protein functions. Cell Host \& Microbe, 28, 752-766.e9.

Baum, J., Gilberger, T. W., Frischknecht, F., \& Meissner, M. (2008). Hostcell invasion by malaria parasites: Insights from plasmodium and toxoplasma. Trends in Parasitology, 24, 557-563.

Baum, J., Richard, D., Healer, J., Rug, M., Krnajski, Z., Gilberger, T. W., ... Cowman, A. F. (2006). A conserved molecular motor drives cell invasion and gliding motility across malaria life cycle stages and other apicomplexan parasites. The Journal of Biological Chemistry, 281, 5197-5208. 
Beck, J. R., Rodriguez-Fernandez, I. A., Cruz de Leon, J., Huynh, M.-H., Carruthers, V. B., Morrissette, N. S., \& Bradley, P. J. (2010). A novel family of toxoplasma IMC proteins displays a hierarchical organization and functions in coordinating parasite division. PLoS Pathogens, 6, e1001094.

Bertiaux, E., Balestra, A. C., Bournonville, L., Louvel, V., Maco, B., SoldatiFavre, D., ... Hamel, V. (2021). Expansion microscopy provides new insights into the cytoskeleton of malaria parasites including the conservation of a conoid. PLoS Biology, 19, e3001020.

Birnbaum, J., Flemming, S., Reichard, N., Soares, A. B., Mesén-Ramírez, P., Jonscher, E., ... Spielmann, T. (2017). A genetic system to study Plasmodium falciparum protein function. Nature Methods, 14, 450-456.

Birnbaum, J., Scharf, S., Schmidt, S., Jonscher, E., Hoeijmakers, W. A. M., Flemming, S., ... Spielmann, T. (2020). A Kelch13-defined endocytosis pathway mediates artemisinin resistance in malaria parasites. Science, 367, 51-59.

Bisio, H., Chaabene, R. B., Sabitzki, R., Maco, B., Baptiste Marq, J., Gilberger, T. W., ... Soldati-Favre, D. (2020). The zip code of vesicle trafficking in apicomplexa: Sec1/munc18 and snare proteins. MBio, 11, $1-21$.

Blackman, M. J., \& Bannister, L. H. (2001). Apical organelles of Apicomplexa: Biology and isolation by subcellular fractionation. Molecular and Biochemical Parasitology, 117, 11-25.

Boucher, M. J., Ghosh, S., Zhang, L., Lal, A., Jang, S. W., Ju, A., ... Yeh, E. (2018). Integrative proteomics and bioinformatic prediction enable a high-confidence apicoplast proteome in malaria parasites. PLoS Biology, 16, e2005895.

Bullen, H. E., Charnaud, S. C., Kalanon, M., Riglar, D. T., Dekiwadia, C., Kangwanrangsan, N., ... Gilson, P. R. (2012). Biosynthesis, localization, and macromolecular arrangement of the Plasmodium falciparum translocon of exported proteins (PTEX). The Journal of Biological Chemistry, 287, 7871-7884.

Bullen, H. E., Tonkin, C. J., O'Donnell, R. A., Tham, W. H., Papenfuss, A. T., Gould, S., ... Gilson, P. R. (2009). A novel family of apicomplexan glideosome-associated proteins with an inner membrane-anchoring role. The Journal of Biological Chemistry, 284, 25353-25363.

Burda, P.-C., Crosskey, T., Lauk, K., Zurborg, A., Söhnchen, C., Liffner, B., ... Gilberger, T. W. (2020). Structure-based identification and functional characterization of a Lipocalin in the malaria parasite Plasmodium falciparum. Cell Reports, 31, 107817.

Bushell, E., Gomes, A. R., Sanderson, T., Anar, B., Girling, G., Herd, C., ... Billker, O. (2017). Functional profiling of a plasmodium genome reveals an abundance of essential genes. Cell, 170, 260-272.e8.

Cabrera, A., Herrmann, S., Warszta, D., Santos, J. M., John Peter, A. T., Kono, M., ... Gilberger, T. W. (2012). Dissection of minimal sequence requirements for Rhoptry membrane targeting in the malaria parasite. Traffic, 13, 1335-1350.

Campelo Morillo, R., Tong, X., Xie, W., Lenz, T., Batugedara, G., Tabassum, N., ... Kafsack, B. F. (2020). Homeodomain protein 1 is an essential regulator of gene expression during sexual differentiation of malaria parasites. bioRxiv, 2020.10.26.352583.

Cavalier-Smith, T. (1993). Kingdom protozoa and its 18 phyla. Microbiological Reviews, 57, 953-994.

Chen, A. L., Kim, E. W., Toh, J. Y., Vashisht, A. A., Rashoff, A. Q., Van, C., ... Bradley, B. J. (2015). Novel components of the toxoplasma inner membrane complex revealed by BiolD. MBio, 6, e02357.

Chen, A. L., Moon, A. S., Bell, H. N., Huang, A. S., Vashisht, A. A., Toh, J. Y. (2017). Novel insights into the composition and function of the toxoplasma IMC sutures. Cellular Microbiology, 19(4), e12678

Collins, C. R., Hackett, F., Strath, M., Penzo, M., Withers-Martinez, C., Baker, D. A., \& Blackman, M. J. (2013). Malaria parasite cGMPdependent protein kinase regulates blood stage Merozoite secretory organelle discharge and egress. PLoS Pathogens, 9, e1003344.

Dearnley, M. K., Yeoman, J. A., Hanssen, E., Kenny, S., Turnbull, L., Whitchurch, C. B., ... Dixon, M. W. A. (2012). Origin, composition, organization and function of the inner membrane complex of Plasmodium falciparum gametocytes. Journal of Cell Science, 125, 2053-2063.

Engelberg, K., Chen, C. T., Bechtel, T., Sánchez Guzmán, V., Drozda, A. A., Chavan, S., ... Gubbels, M. J. (2019). The apical annuli of toxoplasma gondii are composed of coiled-coil and signalling proteins embedded in the inner membrane complex sutures. Cellular Microbiology, 22, e13112.

Ferguson, D. J. P., Sahoo, N., Pinches, R. A., Bumstead, J. M., Tomley, F. M., \& Gubbels, M. J. (2008). MORN1 has a conserved role in asexual and sexual development across the Apicomplexa. Eukaryotic Cell, 7, 698-711.

Ferreira, J. L., Heincke, D., Wichers, J. S., Liffner, B., Wilson, D. W., \& Gilberger, T.-W. (2021). The dynamic roles of the inner membrane complex in the multiple stages of the malaria parasite. Frontiers in Cellular and Infection Microbiology, 10, 841.

Fowler, R. E., Fookes, R. E., Lavin, F., Bannister, L. H., \& Mitchell, G. H. (1998). Microtubules in Plasmodium falciparum merozoites and their importance for invasion of erythrocytes. Parasitology, 117, 425-433.

Franken, H., Mathieson, T., Childs, D., Sweetman, G. M. A., Werner, T., Tögel, I., ... Savitski, M. M. (2015). Thermal proteome profiling for unbiased identification of direct and indirect drug targets using multiplexed quantitative mass spectrometry. Nature Protocols, 10, 1567-1593.

Gao, H., Yang, Z., Wang, X., Qian, P., Hong, R., Chen, X., ... Yuan, J. (2018). ISP1-anchored polarization of $\mathrm{GC} \beta / \mathrm{CDC} 50 \mathrm{~A}$ complex initiates malaria Ookinete gliding motility. Current Biology, 28, 2763-2776.e6.

Gaskins, E., Gilk, S., DeVore, N., Mann, T., Ward, G., \& Beckers, C. (2004). Identification of the membrane receptor of a class XIV myosin in toxoplasma gondii. The Journal of Cell Biology, 165, 383-393.

Geiger, M., Brown, C., Wichers, J. S., Strauss, J., Lill, A., Thuenauer, R., ... Gilberger, T. W. (2020). Structural insights into PfARO and characterization of its interaction with PfAIP. Journal of Molecular Biology, 432, 878-896.

Gilk, S. D., Raviv, Y., Hu, K., Murray, J. M., Beckers, C. J. M., \& Ward, G. E. (2006). Identification of PhIL1, a novel cytoskeletal protein of the toxoplasma gondii pellicle, through photosensitized labeling with 5-[ 125 I]lodonaphthalene-1-Azide. Eukaryotic Cell, 5, 1622-1634.

Gnädig, N. F., Stokes, B. H., Edwards, R. L., Kalantarov, G. F., Heimsch, K. C., Kuderjavy, M., ... Fidock, D. A. (2020). Insights into the intracellular localization, protein associations and artemisinin resistance properties of Plasmodium falciparum K13. PLoS Pathogens, 16, e1008482.

Gould, S. B., Kraft, L. G. K., Van Dooren, G. G., Goodman, C. D., Ford, K. L., Cassin, A. M., ... Waller, R. F. (2011). Ciliate pellicular proteome identifies novel protein families with characteristic repeat motifs that are common to alveolates. Molecular Biology and Evolution, 28, 13191331.

Gould, S. B., Tham, W.-H. H., Cowman, A. F., McFadden, G. I., \& Waller, R. F. (2008). Alveolins, a new family of cortical proteins that define the protist infrakingdom Alveolata. Molecular Biology and Evolution, 25, 1219-1230.

Green, J. L., Wall, R. J., Vahokoski, J., Yusuf, N. A., Mohd Ridzuan, M. A., Stanway, R. R., ... Holder, A. A. (2017). Compositional and expression analyses of the glideosome during the plasmodium life cycle reveal an additional myosin light chain required for maximum motility. The Journal of Biological Chemistry, 292, 17857-17875.

Grüring, C., \& Spielmann, T. (2012). Imaging of live malaria blood stage parasites. Methods in Enzymology, 506, 81-92.

Gubbels, M. J., Vaishnava, S., Boot, N., Dubremetz, J. F., \& Striepen, B. (2006). A MORN-repeat protein is a dynamic component of the toxoplasma gondii cell division apparatus. Journal of Cell Science, 119, 2236-2245.

Harding, C. R., \& Frischknecht, F. (2020). The riveting cellular structures of Apicomplexan parasites. Trends in Parasitology, 36, 979-991.

Healer, J., Crawford, S., Ralph, S., McFadden, G., \& Cowman, A. F. (2002). Independent translocation of two micronemal proteins in developing 
Plasmodium falciparum merozoites. Infection and Immunity, 70, 57515758.

Heiber, A., \& Spielmann, T. (2014). Preparation of parasite protein extracts and Western blot analysis. Bio-Protocol, 4, e1136.

Hortua Triana, M. A., Márquez-Nogueras, K. M., Chang, L., Stasic, A. J., Li, C., Spiegel, K. A., ... Moreno, S. N. J. (2018). Tagging of weakly expressed toxoplasma gondii calcium-related genes with high-affinity tags. The Journal of Eukaryotic Microbiology, 65, 709-721.

Hu, G., Cabrera, A., Kono, M., Mok, S., Chaal, B. K., Haase, S., ... Bozdech, Z. (2010). Transcriptional profiling of growth perturbations of the human malaria parasite Plasmodium falciparum. Nature Biotechnology, 28, 91-98.

$\mathrm{Hu}, \mathrm{K}$. (2008). Organizational changes of the daughter basal complex during the parasite replication of toxoplasma gondii. PLoS Pathogens, 4, 108-121.

Hu, K., Johnson, J., Florens, L., Fraunholz, M., Suravajjala, S., DiLullo, C., ... Murray, J. M. (2006). Cytoskeletal components of an invasion machine - the apical complex of toxoplasma gondii. PLoS Pathogens, 2, 121-138.

Ito, D., Takashima, E., Yamasaki, T., Hatano, S., Hasegawa, T., Miura, K., ... Tsuboi, T. (2019). Antibodies against a Plasmodium falciparum RON12 inhibit merozoite invasion into erythrocytes. Parasitology International, 68, 87-91.

Jones, M. L., Kitson, E. L., \& Rayner, J. C. (2006). Plasmodium falciparum erythrocyte invasion: A conserved myosin associated complex. Molecular and Biochemical Parasitology, 147, 74-84.

Jonscher, E., Flemming, S., Schmitt, M., Sabitzki, R., Reichard, N., Birnbaum, J., ... Spielmann, T. (2019). PfVPS45 is required for host cell cytosol uptake by malaria blood stage parasites. Cell Host \& Microbe, 25, 166-173.e5.

Keeley, A., \& Soldati, D. (2004). The glideosome: A molecular machine powering motility and host-cell invasion by Apicomplexa. Trends in Cell Biology, 14, 528-532.

Kehrer, J., Frischknecht, F., \& Mair, G. R. (2016). Proteomic analysis of the plasmodium berghei gametocyte egressome and vesicular bioid of osmiophilic body proteins identifies merozoite trap-like protein (MTRAP) as an essential factor for parasite transmission. Molecular \& Cellular Proteomics, 15, 2852-2862.

Kehrer, J., Ricken, D., Strauss, L., Pietsch, E., Heinze, J. M., \& Frischknecht, F. (2020). APEX-based proximity labeling in plasmodium identifies a membrane protein with dual functions during mosquito infection 2 3. bioRxiv, 2020.09.29.318857.

Khater, E. I., Sinden, R. E., \& Dessens, J. T. (2004). A malaria membrane skeletal protein is essential for normal morphogenesis, motility, and infectivity of sporozoites. The Journal of Cell Biology, 167, 425-432.

Khosh-Naucke, M., Becker, J., Mesén-Ramírez, P., Kiani, P., Birnbaum, J., Fröhlke, U., ... Spielmann, T. (2018). Identification of novel parasitophorous vacuole proteins in $P$. falciparum parasites using BiolD. International Journal of Medical Microbiology, 308, 13-24.

Knuepfer, E., Suleyman, O., Dluzewski, A. R., Straschil, U., O'Keeffe, A. H., Ogun, S. A., ... Holder, A. A. (2014). RON12, a novel plasmodiumspecific rhoptry neck protein important for parasite proliferation. Cellular Microbiology, 16, 657-672.

Kono, M., Heincke, D., Wilcke, L., Wong, T. W. Y., Bruns, C., Herrmann, S., ... Gilberger, T. W. (2016). Pellicle formation in the malaria parasite. Journal of Cell Science, 129, 673-680.

Kono, M., Herrmann, S., Loughran, N. B., Cabrera, A., Engelberg, K., Lehmann, C., ... Gilberger, T. W. (2012). Evolution and architecture of the inner membrane complex in asexual and sexual stages of the malaria parasite. Molecular Biology and Evolution, 29, 2113-2132.

Kono, M., Prusty, D., Parkinson, J., \& Gilberger, T. W. (2013). The apicomplexan inner membrane complex. Frontiers in Bioscience, 18, 982-992.

Koreny, L., Zeeshan, M., Barylyuk, K., Tromer, E. C., van Hooff, J. J. E., Brady, D., ... Waller, R. F. (2021). Molecular characterization of the conoid complex in toxoplasma reveals its conservation in all apicomplexans, including plasmodium species. PLoS Biology, 19, e3001081.

Lambros, C., \& Vanderberg, J. P. (1979). Synchronization of Plasmodium falciparum Erythrocytic stages in culture. The Journal of Parasitology, 65, 418.

Lee, R. E., \& Kugrens, P. (1992). Relationship between the flagellates and the ciliates. Microbiological Reviews, 56, 529-542.

Lentini, G., Dubois, D. J., Maco, B., Soldati-Favre, D., \& Frénal, K. (2019). The roles of Centrin 2 and dynein light chain $8 a$ in apical secretory organelles discharge of toxoplasma gondii. Traffic, 20, 583-600.

Leung, J. M., Liu, J., Wetzel, L. A., \& Hu, K. (2019). Centrin2 from the human parasite toxoplasma gondii is required for its invasion and intracellular replication. Journal of Cell Science, 132, jcs228791.

Leung, J. M., Nagayasu, E., Hwang, Y. C., Liu, J., Pierce, P. G., Phan, I. Q., ... $\mathrm{Hu}, \mathrm{K}$. (2020). A doublecortin-domain protein of toxoplasma and its orthologues bind to and modify the structure and organization of tubulin polymers. BMC Molecular and Cell Biology, 21, 8.

Liu, W., Xie, Y., Ma, J., Luo, X., Nie, P., Zuo, Z., ... Ren, J. (2015). IBS: An illustrator for the presentation and visualization of biological sequences. Bioinformatics, 31, 3359-3361.

López-Barragán, M. J., Lemieux, J., Quiñones, M., Williamson, K. C., Molina-Cruz, A., Cui, K., ... Su, X. (2011). Directional gene expression and antisense transcripts in sexual and asexual stages of Plasmodium falciparum. BMC Genomics, 12, 587.

Malleret, B., Claser, C., Ong, A. S. M., Suwanarusk, R., Sriprawat, K., Howland, S. W., ... Rénia, L. (2011). A rapid and robust tri-color flow cytometry assay for monitoring malaria parasite development. Scientific Reports, 1, 118.

McIntosh, M. T., Drozdowicz, Y. M., Laroiya, K., Rea, P. A., \& Vaidya, A. B. (2001). Two classes of plant-like vacuolar-type $\mathrm{H}+$-pyrophosphatases in malaria parasites. Molecular and Biochemical Parasitology, 114, 183-195.

Mesén-Ramírez, P., Bergmann, B., Tran, T. T., Garten, M., Stäcker, J., Naranjo-Prado, I., ... Spielmann, T. (2019). EXP1 is critical for nutrient uptake across the parasitophorous vacuole membrane of malaria parasites. PLoS Biology, 17, e3000473.

Mesén-Ramírez, P., Reinsch, F., Blancke Soares, A., Bergmann, B., Ullrich, A. K., Tenzer, S., \& Spielmann, T. (2016). Stable translocation intermediates jam global protein export in Plasmodium falciparum parasites and link the PTEX component EXP2 with translocation activity. PLoS Pathogens, 12, e1005618.

Mitchell, A. L., Attwood, T. K., Babbitt, P. C., Blum, M., Bork, P., Bridge, A., ... Finn, R. D. (2019). InterPro in 2019: Improving coverage, classification and access to protein sequence annotations. Nucleic Acids Research, 47, D351-D360.

Moon, R. W., Hall, J., Rangkuti, F., Ho, Y. S., Almond, N., Mitchell, G. H., ... Blackman, M. J. (2013). Adaptation of the genetically tractable malaria pathogen plasmodium knowlesi to continuous culture in human erythrocytes. Proceedings of the National Academy of Sciences, 110, 531-536.

Morrissette, N. S., \& Sibley, L. D. (2002). Cytoskeleton of Apicomplexan parasites. Microbiology and Molecular Biology Reviews, 66, 21-38.

Parkyn Schneider, M., Liu, B., Glock, P., Suttie, A., McHugh, E., Andrew, D., ... Dixon, M. W. A. (2017). Disrupting assembly of the inner membrane complex blocks Plasmodium falciparum sexual stage development. PLoS Pathogens, 13, e1006659.

Perrin, A. J., Collins, C. R., Russell, M. R. G., Collinson, L. M., Baker, D. A., \& Blackman, M. J. (2018). The actinomyosin motor drives malaria parasite red blood cell invasion but not egress. MBio, 9, e00905-e00918.

Peterson, M. G., Marshall, V. M., Smythe, J. A., Crewther, P. E., Lew, A., Silva, A., ... Kemp, D. J. (1989). Integral membrane protein located in the apical complex of Plasmodium falciparum. Molecular and Cellular Biology, 9, 3151-3154. 
Prommana, P., Uthaipibull, C., Wongsombat, C., Kamchonwongpaisan, S., Yuthavong, Y., Knuepfer, E., ... Shaw, P. J. (2013). Inducible knockdown of plasmodium gene expression using the gImS ribozyme. PLoS One, 8 , e73783.

Rivadeneira, E., Wasserman, M., \& Espinal, C. (1983). Separation and concentration of Schizonts of Plasmodium falciparum by Percoll gradients. The Journal of Protozoology, 30, 367-370.

Roux, K. J., Kim, D. I., Raida, M., \& Burke, B. (2012). A promiscuous biotin ligase fusion protein identifies proximal and interacting proteins in mammalian cells. The Journal of Cell Biology, 196, 801-810.

Rudlaff, R. M., Kraemer, S., Streva, V. A., \& Dvorin, J. D. (2019). An essential contractile ring protein controls cell division in Plasmodium falciparum. Nature Communications, 10, 2181.

Russell, D. G., \& Burns, R. G. (1984). The polar ring of coccidian sporozoites: A unique microtubule-organizing Centre. Journal of Cell Science, 65, 193-207.

Saini, E., Zeeshan, M., Brady, D., Pandey, R., Kaiser, G., Koreny, L., ... Tewari, R. (2017). Photosensitized INA-Labelled protein 1 (PhIL1) is novel component of the inner membrane complex and is required for plasmodium parasite development. Scientific Reports, 7, 15577.

Schindelin, J., Arganda-Carreras, I., Frise, E., Kaynig, V., Longair, M., Pietzsch, T., ... Cardona, A. (2012). Fiji: An open-source platform for biological-image analysis. Nature Methods, 9, 676-682.

Schnider, C. B., Bausch-Fluck, D., Brühlmann, F., Heussler, V. T., \& Burda, P.-C. (2018). BiolD reveals novel proteins of the plasmodium parasitophorous vacuole membrane. mSphere, 3, e00522.

Sinden, R. E. (1982). Gametocytogenesis of Plasmodium falciparum in vitro: An electron microscopic study. Parasitology, 84, 1-11.

Soldati, D., Foth, B. J., \& Cowman, A. F. (2004). Molecular and functional aspects of parasite invasion. Trends in Parasitology, 20, 567-574.

Sonnhammer, E. L., von Heijne, G., \& Krogh, A. (1998). A hidden Markov model for predicting transmembrane helices in protein sequences. Proceedings/International Conference on Intelligent Systems for Molecular Biology, 6, 175-182.

Spielmann, T., Gras, S., Sabitzki, R., \& Meissner, M. (2020). Endocytosis in plasmodium and toxoplasma parasites. Trends in Parasitology, 36, 520-532.

Straimer, J., Gnädig, N. F., Witkowski, B., Amaratunga, C., Duru, V., Ramadani, A. P., ... Fidock, D. A. (2015). K13-propeller mutations confer artemisinin resistance in Plasmodium falciparum clinical isolates. Science, 347, 428-431.

Struck, N. S., de Souza Dias, S., Langer, C., Marti, M., Pearce, J. A., Cowman, A. F., \& Gilberger, T. W. (2005). Re-defining the Golgi complex in Plasmodium falciparum using the novel Golgi marker PfGRASP. Journal of Cell Science, 118, 5603-5613.

Suvorova, E. S., Francia, M., Striepen, B., \& White, M. W. (2015). A novel bipartite centrosome coordinates the Apicomplexan cell cycle. PLoS Biology, 13(3), e1002093.

Torres, J. A., Pasquarelli, R. R., Back, P. S., Moon, A. S., \& Bradley, P. J. (2021). Identification and molecular dissection of IMC32, a conserved Toxoplasma inner membrane complex protein that is essential for parasite replication. MBio, 12, e03622.

Trager, W, \& Jensen, J. B. (1997). Continuous culture of Plasmodium falciparum: Its impact on malaria research. International Journal for Parasitology, 27, 989-1006. https://doi.org/10.1016/S0020-7519(97)00080-5.

Tran, J. Q., De Leon, J. C., Li, C., Huynh, M. H., Beatty, W., \& Morrissette, N. S. (2010). RNG1 is a late marker of the apical polar ring in toxoplasma gondii. Cytoskeleton, 67, 586-598.

Tremp, A. Z., Al-Khattaf, F. S., \& Dessens, J. T. (2014). Distinct temporal recruitment of plasmodium alveolins to the subpellicular network. Parasitology Research, 113, 4177-4188.
Vizcaíno, J. A., Csordas, A., Del-Toro, N., Dianes, J. A., Griss, J., Lavidas, I. (2016). 2016 update of the PRIDE database and its related tools. Nucleic Acids Research, 44, D447-D456.

Wall, R. J., Roques, M., Katris, N. J., Koreny, L., Stanway, R. R., Brady, D. (2016). SAS6-like protein in plasmodium indicates that conoidassociated apical complex proteins persist in invasive stages within the mosquito vector. Scientific Reports, 6, 28604.

Wall, R. J., Zeeshan, M., Katris, N. J., Limenitakis, R., Rea, E., Stock, J. (2019). Systematic analysis of plasmodium myosins reveals differential expression, localisation, and function in invasive and proliferative parasite stages. Cellular Microbiology, 21(10), e13082.

Walliker, D., Quakyi, I. A., Wellems, T. E., McCutchan, T. F., Szarfman, A., London, W. T., ... Carter, R. (1987). Genetic analysis of the human malaria parasite Plasmodium falciparum. Science, 236, 1661-1666.

Werner, E. B., Taylor, W. R., \& Holder, A. A. (1998). A plasmodium chabaudi protein contains a repetitive region with a predicted spectrin-like structure. Molecular and Biochemical Parasitology, 94, 185-196.

Wetzel, J., Herrmann, S., Swapna, L. S., Prusty, D., Peter, A. T. J., Kono, M., ... Gilberger, T. W. (2015). The role of palmitoylation for protein recruitment to the inner membrane complex of the malaria parasite. The Journal of Biological Chemistry, 290, 1712-1728.

Wichers, J. S., Scholz, J. A. M., Strauss, J., Witt, S., Lill, A., Ehnold, L. I., ... Bachmann, A. (2019). Dissecting the gene expression, localization, membrane topology, and function of the Plasmodium falciparum STEVOR protein family. MBio, 10, e01500e01519.

Yang, T., Yeoh, L. M., Tutor, M. V., Dixon, M. W., McMillan, P. J., Xie, S. C., ... Cobbold, S. A. (2019). Decreased K13 abundance reduces hemoglobin catabolism and Proteotoxic stress, underpinning Artemisinin resistance. Cell Reports, 29, 2917-2928.e5.

Zanghì, G., Vembar, S. S., Baumgarten, S., Ding, S., Guizetti, J., Bryant, J. M., ... Scherf, A. (2018). A specific PfEMP1 is expressed in $P$. falciparum Sporozoites and plays a role in hepatocyte infection. Cell Reports, 22, 2951-2963.

Zhang, M., Wang, C., Otto, T. D., Oberstaller, J., Liao, X., Adapa, S. R., ... Adams, J. H. (2018). Uncovering the essential genes of the human malaria parasite Plasmodium falciparum by saturation mutagenesis. Science, 360, eaap7847.

\section{SUPPORTING INFORMATION}

Additional supporting information may be found online in the Supporting Information section at the end of this article.

How to cite this article: Wichers, J. S., Wunderlich, J., Heincke, D., Pazicky, S., Strauss, J., Schmitt, M., Kimmel, J., Wilcke, L., Scharf, S., von Thien, H., Burda, P.-C., Spielmann, T., Löw, C., Filarsky, M., Bachmann, A., \& Gilberger, T. W. (2021). Identification of novel inner membrane complex and apical annuli proteins of the malaria parasite Plasmodium falciparum. Cellular Microbiology, 23(9), e13341. https://doi.org/10. 1111/cmi.13341 